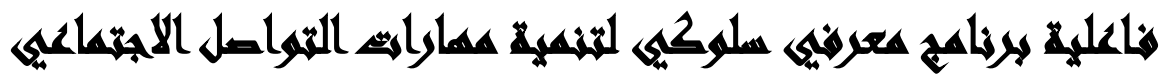

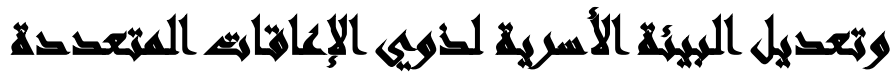

\section{[9]}

محمد سعد الدين السيد(')- أسماء محمد السرسى(ץ) - محمد عبد العدل الصاوى(ז)

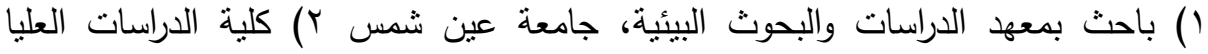

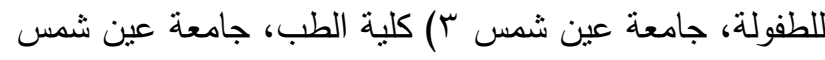

\section{المستصنص:}

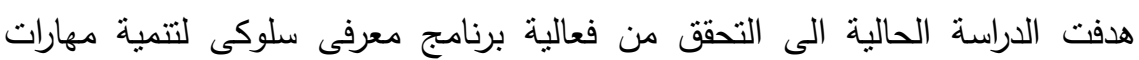

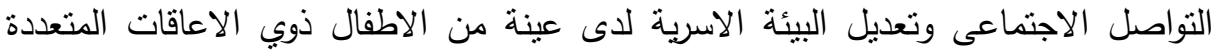

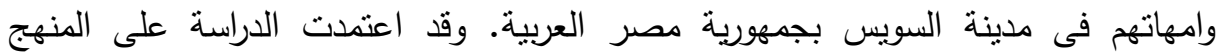

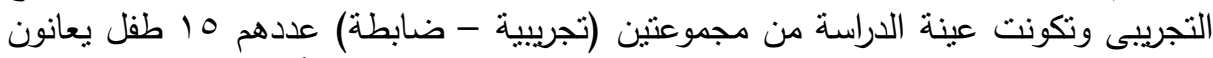

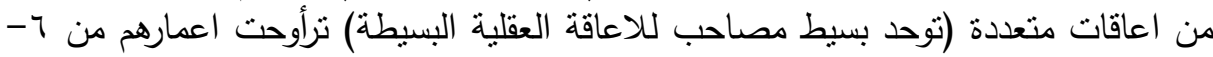

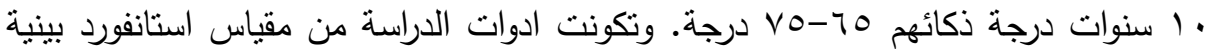

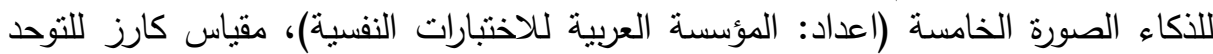

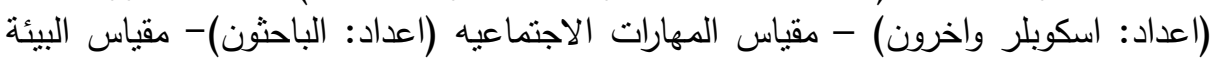

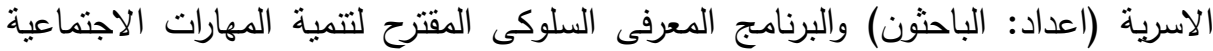

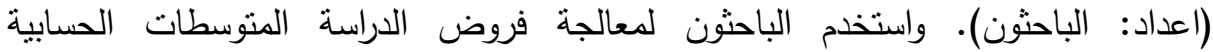

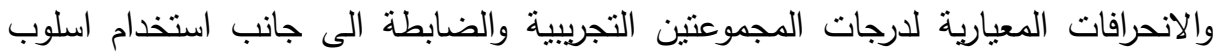

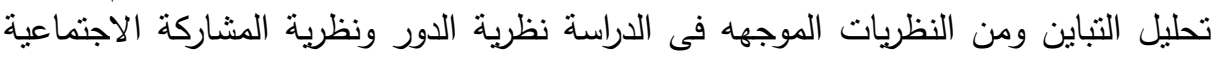
ونظريات الاتصال فى علم النفس وعلم الاجتماع، والنظرية المعرفية السلوكية.

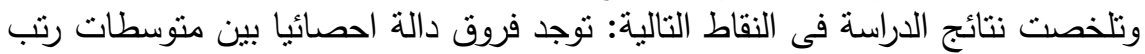

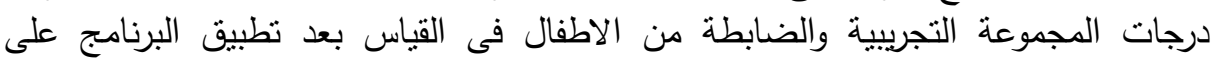

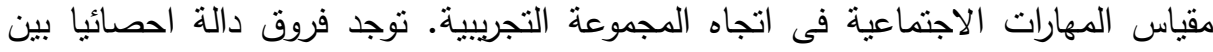

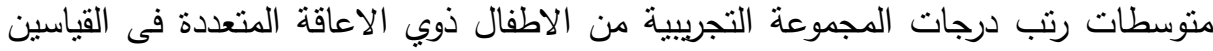

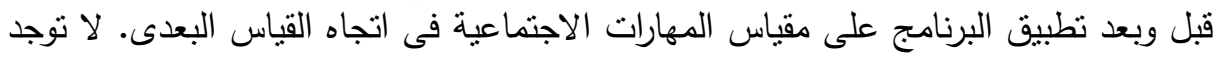

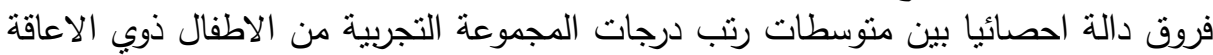

المتعددة فى القياسين البعدى والتتبعى لتطبيق البرناج على مقياس المهارات الاجتماعية.

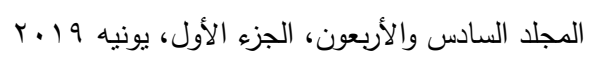


كما توجد فروق ذات دلالة احصائية بين منوسط درجات رثب القياسين القبلى والبعدى الإئي

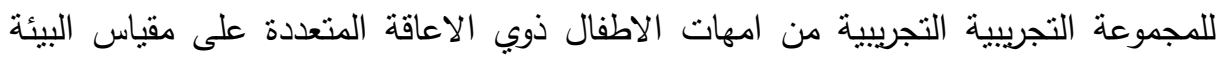

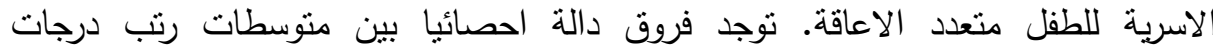

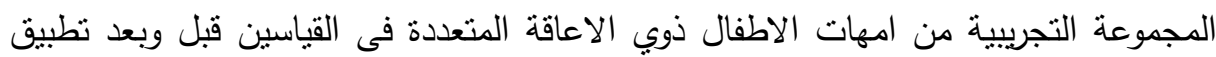

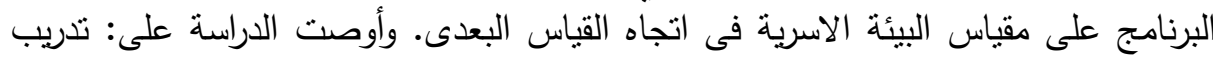

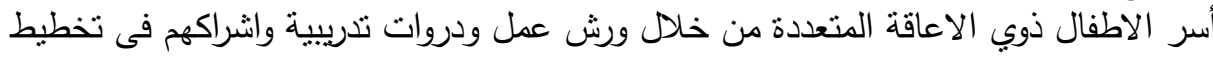

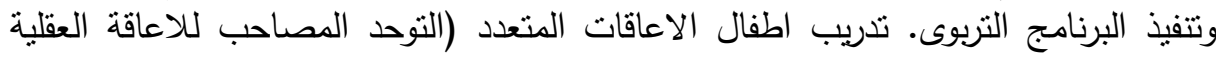

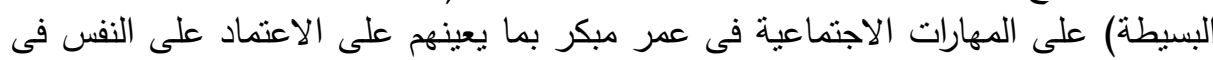

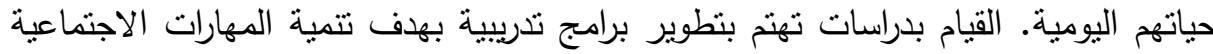

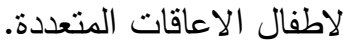

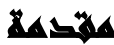

يعد طفل ذو الإحتياجات الخاصة مصدر للضغوط النفسية للاباء حيث يعانون من المشكلات نتيجة إصابة الطفل بإعاقة متل التوحد أو الاعاقة العقلية أو التلعثم ... وغيرها من لناه انواع الإعاقات، لكن اله خلق مع المحن الصبر والجلد وخلق معهما الأمل فى غد أفضل إلفل بإذن لله.

إن نمو الطفل يكون محكوماً بعنصرين مركبين ومتفاعلين ومتكاملين معاً وهما جسده وبيئته التى يشب وبتطور فيها، ويتشكل البنيان الجسدى متأثرا بالسمات البدنية والنفسية

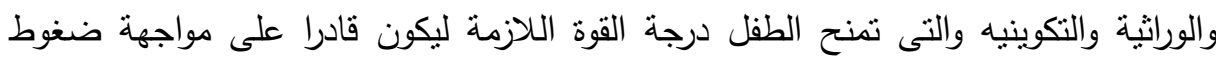
الحياة التى يعيش فيها ويتفاعل معها تأثرا وتأثيرا.

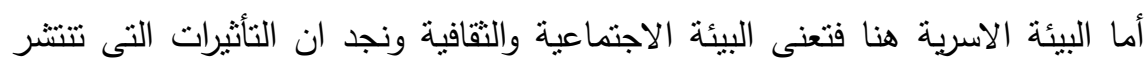

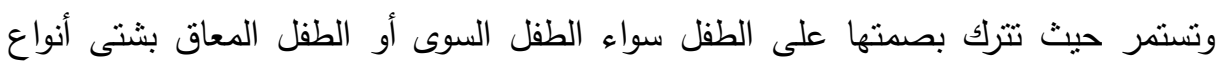

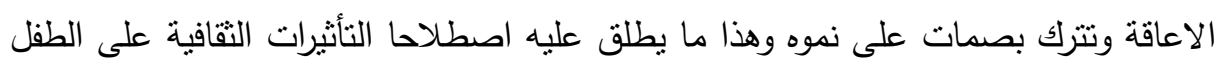

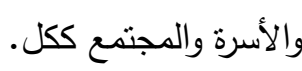
ولا تبدو هذه الثقافة فى مجرد النظم واللغه والقيم المعنوية والبدنية والتنظيم الاجتماعى

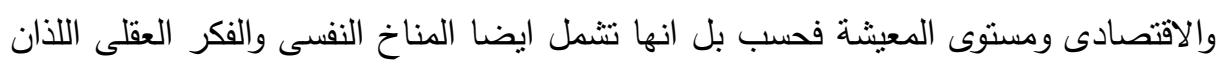

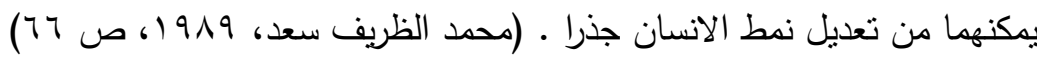


وفى هذا المسعى تتبلور الدراسة الحالية وموضوعها: "فاعلية برنامج معرفى سلوكى

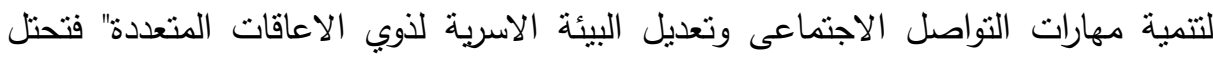

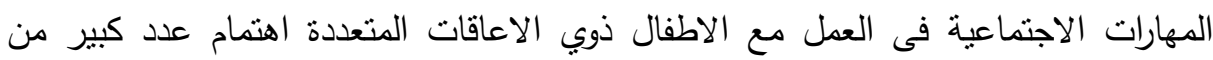

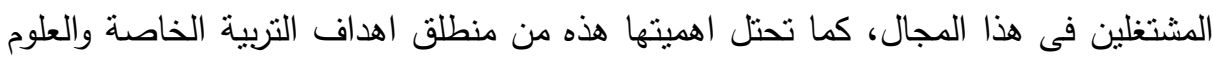
الانسانية النى تسعى الى مساعدة الاطفال ذوي الاعاقات المتعددة فى تحقيق اكبر قدر مدكن الهن من التوافق النفسى والتكيف الاجتماعى حتى يصبحوا مواطنين صالحين ومنتجين يمكن

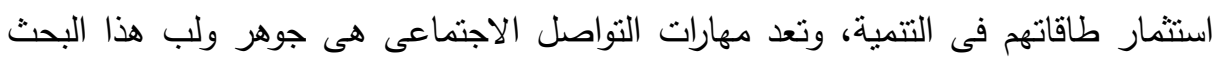

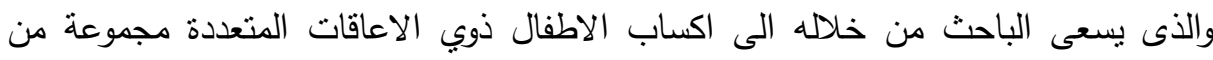

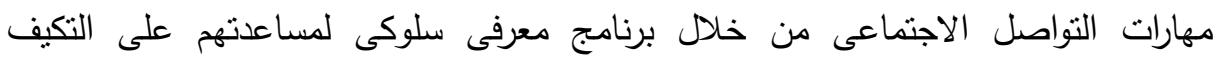
الاجتماعى داخل بيئاتهم المختلفة ،مما يساعدهم على تعديل البيئة الاسرية التى يعيشون بها.

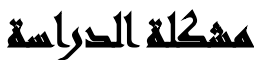

تعد أنشكال وأنواع التذخل لتحسين أداءات الاطفال المعاقين اجتماعيا من السمات البارزة للتحول من النموذج الطبى Medical Model فى الرعاية الذى يركز على الطفل وحاجاته الى النموذج البيئى Ecological Model الذى يركز على الطفل و بيئته التى يعيش فيها

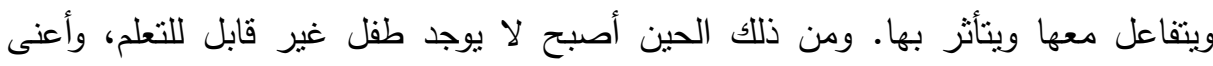

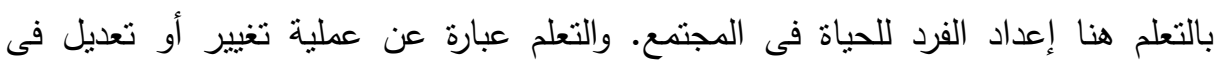

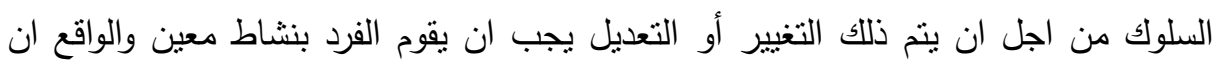

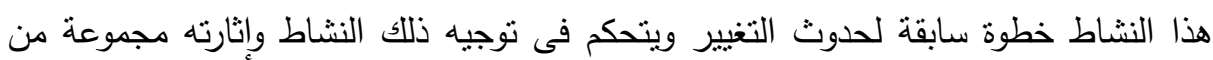

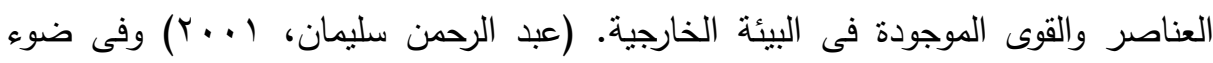
الاهتمام الملحوظ والمتزايد فى العقود الثناث الماضية بالطفل ذوي الاحتباجات الخاصة وكيفية اكسابه مهارات التواصل الاجتماعى اللازمه لحياته، وفى ضوء شكوى أولياء الامور وكذللك

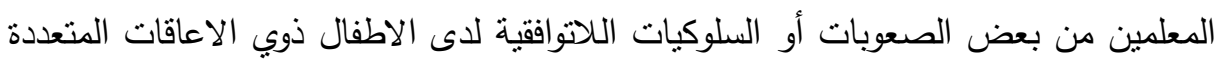

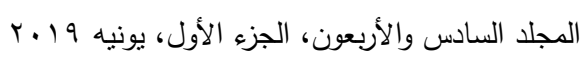


ومن خلال عمل الباحث كاخصائى نفسى ومسئول عن البرامج الخاصة فى مجال الاعداد

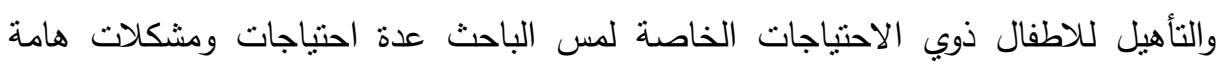

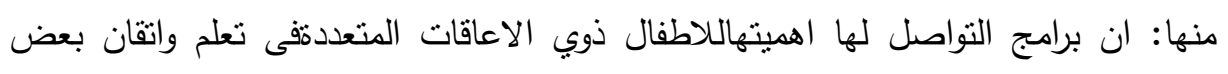

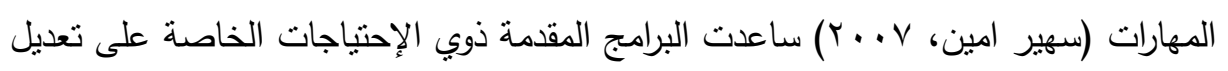

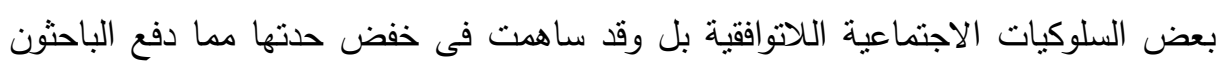

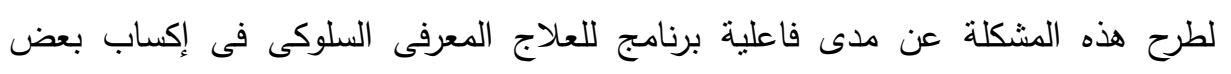

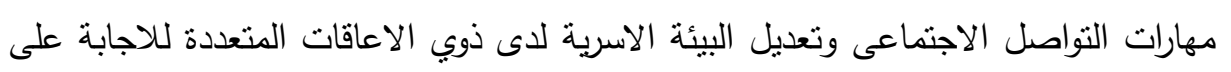

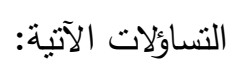

ا. هل توجد فروق بين المجموعة التجربيية والضابطة من الاطفال ذوي الاعاقات المتعددة

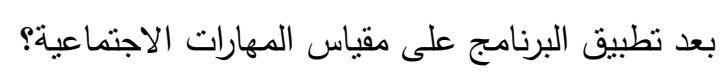

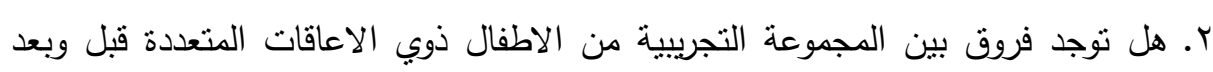

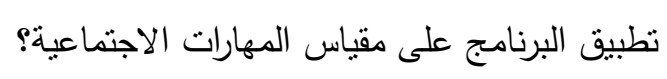

r. هل توجد فروق بين المجموعة التجريبية من الاطفال ذوي الاعاقة المتعددة فى القياسين

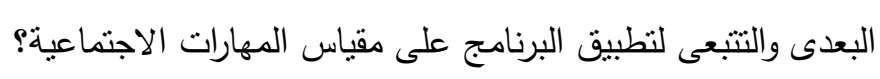

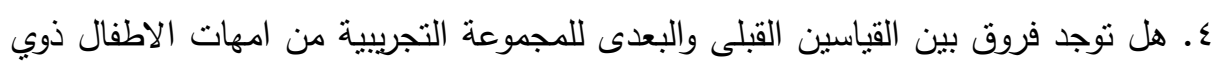

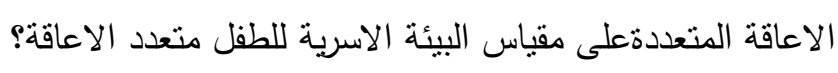

ه. هل توجد فروق بين المجموعة التجريبية من امهات الاطفال ذوبي الاعاقة المتعددة قبل الاعبديه

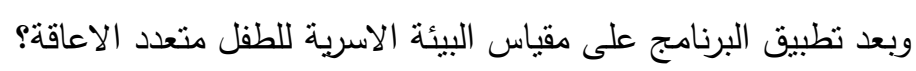

\section{أهسا هن البرواسمة}

ا - التحقق من فاعلية برنامج معرفى سلوكى فى تتمية المهارات الاجتماعية لذوي الاعاقات

$$
\text { المتعددة. }
$$

r- التحقق من فاعلية برنامج معرفى سلوكى فى تعديل البيئة الاسرية لأسر ذوي الاعاقات 


\section{أهمية الصراسما}

الأهمية النظريةة: إلقاء الضوء على الاطفال ذوي الاحتباجات الخاصة (الاعاقات المتعددة)

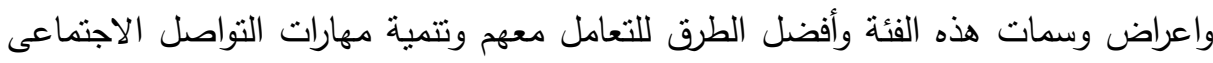
لديهم معرفة مدى نطور مهارات التواصل الإجتماعى من نطبيق برنامج معرفى سلوكلنتمية مهارات التواصل الاجتماعى للاطفال ذوي الاحتياجات الخاصة (الاعاقات المتعددة). الأهمية التطبيقية: - إمداد الاباء بالتغذية المرتدة الفعالة والكافية عن الاطفال ذوي الاحتباجات الخاصة (الاعاقات المتعددة) وافضل الاساليب التربوية والمهنية فى التعامل معهم لتتمية مهارات التواصل الاجنماعى لديهم. - تتمية مهارات التواصل الاجتماعى لاى الاطفال ذوبي الاحتباجات الخاصة (الاعاقات (المتعددة) - امداد الاباء ببعض الاساليب الفنية المستخدمة فى البرنامج ومساعدتهم فى تطبيقها فى

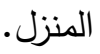

\section{مغاهميد التوراسم}

الطقل متعدد الاعاقة: يعرفهم عبد الرحمن سليمان بانهم هؤلاء الذين يحتاجون طوال

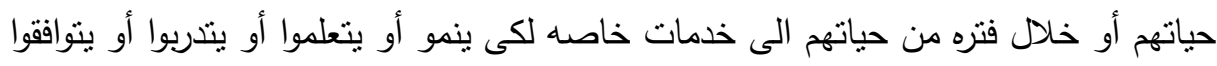

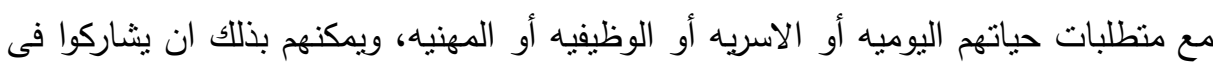

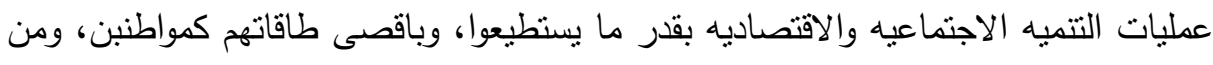

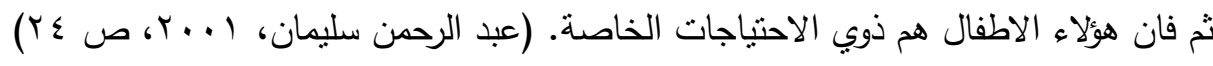

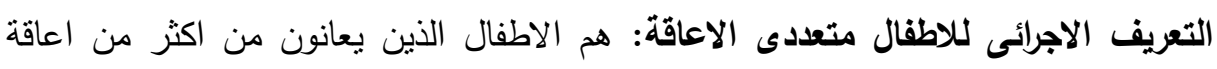

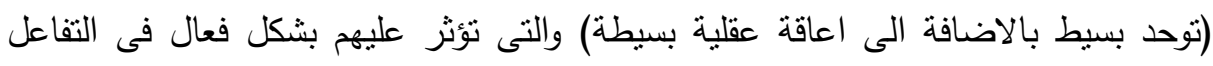

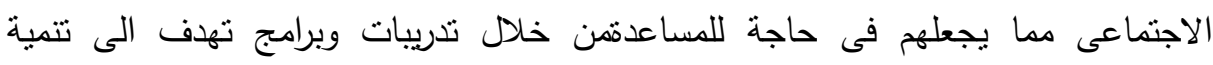


مهاراتهم الاجتماعيه لمساعدتهم على استغلال قدراتهم وتطويرها للتغلب على اعاقتهم

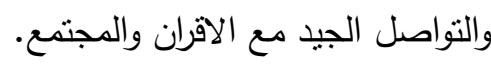
برنامج: تعنى كلمة برنامج فى قاموس المعجم الوسيط انه الخطة المرسومة لعمل ما وهو مجموعة من الخبرات التى يتعر ض لها الافراد بطريقة معروفة ومحددة بهدف اكتسابهم معلومات أو مهارات أو اتجاهات فى جانب محدد من جوانب سلوكهم (ليلى كرم الدين،

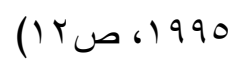
التعريف الاجرائى: هو مجموعة من الاجراءات الارشادية التوجيهية المخططة على اسس

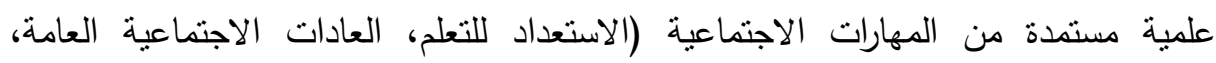

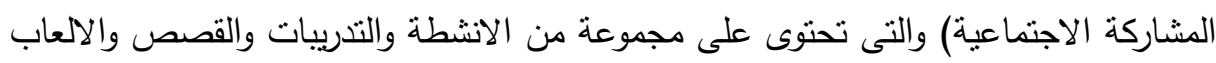
المتضمنه بعض الفنيات والاساليب المستخدمة لتتمية المهارات الاجتماعية لدى الإلى الطفال متعددى الاعاقة. العلاج المعرفى السلوكى: يعتبر العلاج المعرفى السلوكى اتجاهاً علاجياً حديثاً نسبياً يعمل على الدمج بين العلاج المعرفى بفنياته المتعدده والعلاج السلوكى بما يضمنه من فنيات ويعدد الى النعامل مع الاضطرابات المختلفة من منظور ثناثى الابعاد أو يتعامل معها معرفياً

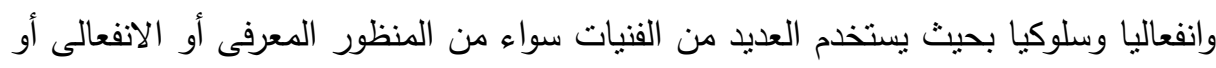

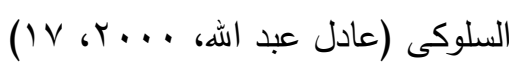

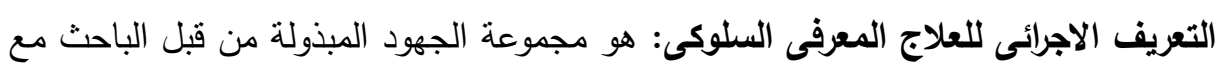

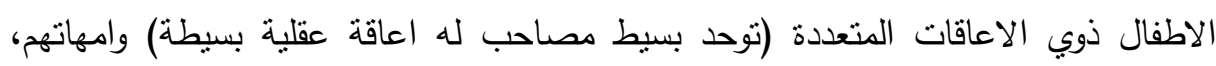
تتضمن تلك الجهود الخدمات الارشادية والتدريبية التى تهدف تتمية المهارات الاجتماعية للطفل متعدد الاعاقة وتعديل البيئة الاسرية فى ضوء الاستس العلمية والمهنية للمدخل المعرفى لإنى السلوكى.

المهارات الاجتماعية: تعتبر المهارة الاجتماعية مكونا اساسيا من مكونات الثخصية

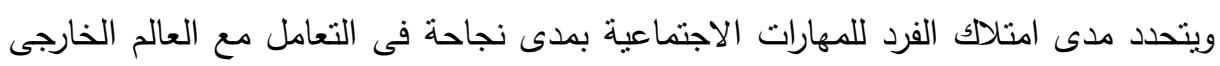

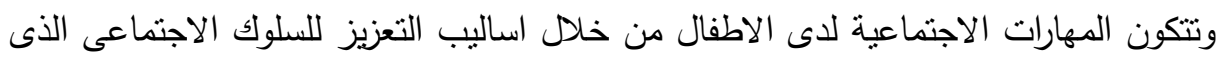

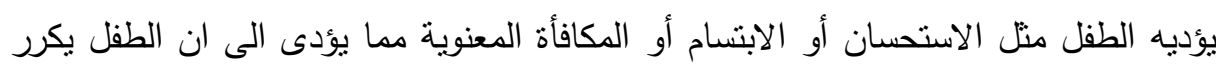
178

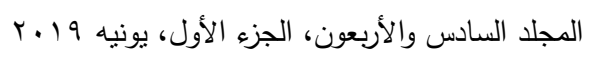


مثل هذا السلوك اما عدم الموافقة أو النقد الثفهى أو التهجم والعبوس يجعل الطفل يكف عن

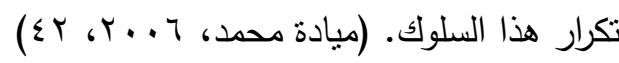
التعريف الاجرائى للمهارات الاجتماعية: المهارات الاجتماعية هى على عادات مفيدة اجتماعيا

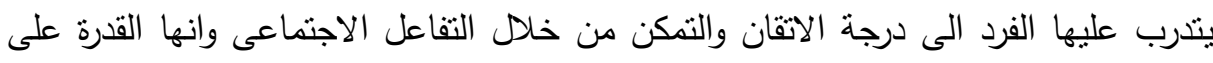

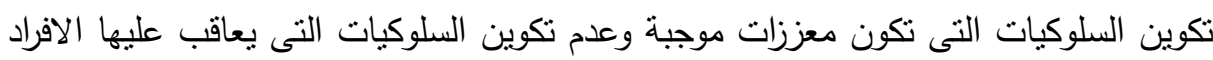
الذين يميلون لاظهار السلوك الاخر يكون فى الغالب غير مؤهلين اجتماعيا ولابد من تدريبهج على المهارات الاجتماعية. فهى مجموعة من الاستجابات التى تصدر عن الطفل كمنبهات اجتماعية معينه والتى تتمثل فى القدرة على التفاعل مع الاخرين والقدرة على تكوين علاقات التهات التهات اجتماعية مناسبة.

تعديل البيئة: أى عملية تعديل السلوك غير المرغوب والسلوك البيئى الخاطئ ايضا ينت على ثمانى خطوات اساسية هى بتحديد السلوك المستهدف وتعريفه وقياسه وبتحليله وظيفيا وتصميم خطة العلاج وتتفيذ تلك الخطة وتقييم فعالية برنامج العلاج واخيرا تلخيص النتائج

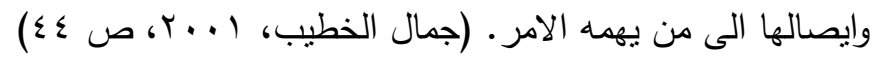
التعريف الاجرائى للبيئة الأسرية: هى البيئة الاجتماعية الأولى التى يبدأ فيها الطفل تكوين

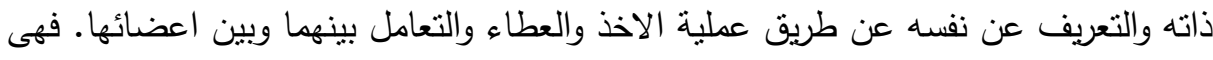
مسرح التفاعل الذى يتم فيه النمو والتعلم والعالم الصغير للطفل الذى به تتكون خبراته عن الناس والاثياء والمواقف.

\section{هغوضر التواسمة}

1-توجد فروق دالة احصائيا بين متوسطات رتب درجات المجموعة التجريبية والضابطة من الاطفال فى القياس بعد تطبيق البرنامج على مقياس المهارات الاجتماعية فى اتجاه

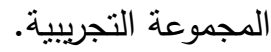


r-توجد فروق دالة احصائيا بين منوسطات رتب درجات المجموعة التجريبية من الاطفال ذوي الاعاقات المتعددة فى القياسين قبل وبعد تطبيق البرنامج على مقياس المهارات الاجتماعية فى اتجاه القياس البعدى.

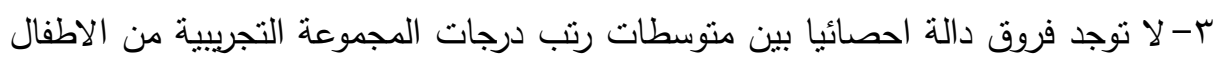

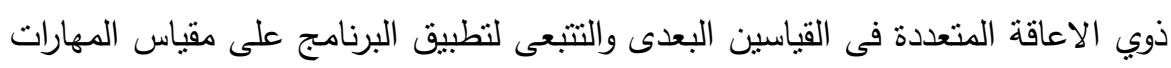
الاجتماعية.

ع-توجد فروق ذات دلالة احصائية بين منوسط رثب درجات القياسين القبلى والبعدى لللجموعة التجريبية (امهات) على مقياس البيئة الاسرية للطفل متعدد الاعاقة.

ه-توجد فروق دالة احصائيا بين متوسطات رتب درجات المجموعة التجريبية من امهات الاطفال ذوبي الاعاقة المتعددة فى القياسين قبل وبعد نطبيق البرنامج على مقيط دئس درجات البيئة

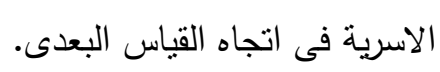

\section{التوراسايت الساريخة}

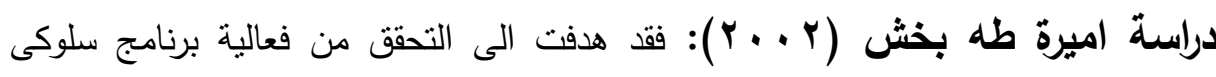

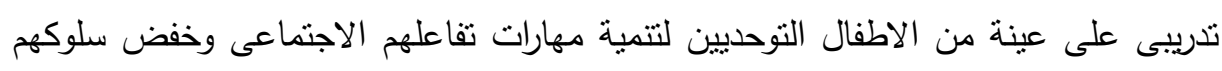

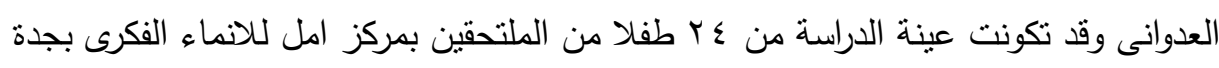

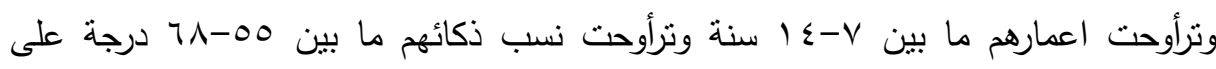

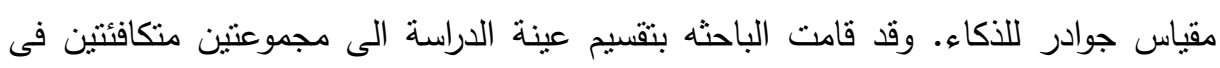

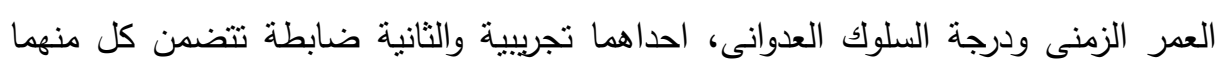

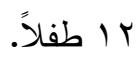

وتوصلت الدراسة الى فعالية البرنامج فى خفض السلوك العدوانى لدى عينة الدراسة حيث وجدت فروق ذات دلالة احصائية بين متوسطات درجات المجموعنين التجريبية والضابطة فى القياس البعدى للسلوك العدوانى. ووجدت فروق ذات دلاتلة احصائية بين متوسطى درجات المجموعة التجريبية فى القياسين القبلى والبعدى للسلوك العدوانى وابعاده. 


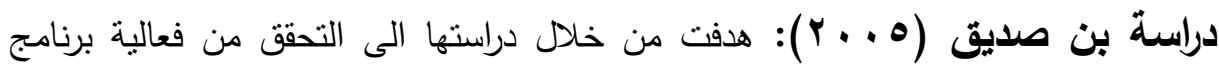
تدريبى قامت بتقديمه بهدف تنمية مهارات التواصل الغير لفظى واثره على السلوك الاجتماعى

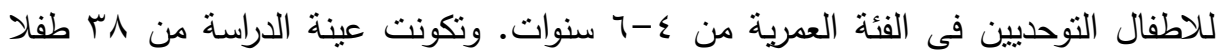
توحديا وتم تقسيمهم الى مجموعه ضابطة ومجموعه تجريبيه. واظهرت النتائج فعالية البرنامج التدريبى فى تتمية مهارات التواصل غير اللفظى للمجموعه التجريبية كما اظهرت النتائج الى عدم فعالية البرنامج فى تتمية السلوك الاجتماعى المناسب لافراد المجموعه التجريبية كما اثارت النتائج الى فعالية البرنامج التنريبى فى خفض السلوك الاجتماعى غير المناسب لدى المجموعه التجريبية.

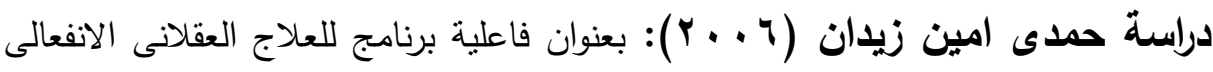

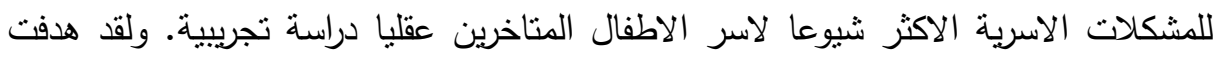

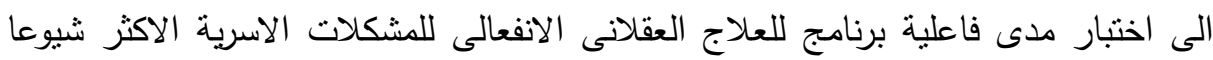

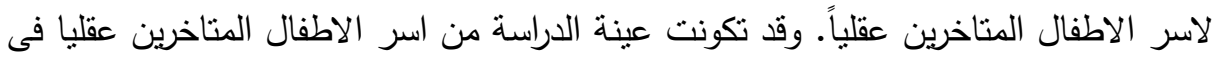
المرحلة العمرية من (9-0 (1) سنة وتم القياس القبلى للمجموعة التجريبية ثم تطبيق برنامج العلاج العقلانى الانفعالى باساليبة المختلفة ثم تم القياس البعدى وتم مقارنة نتائج القياسين القبلى والبعدى للوصول الى النتيجة النهائية. وطبق الباحث الادوات الآتية: برنامج العلاج

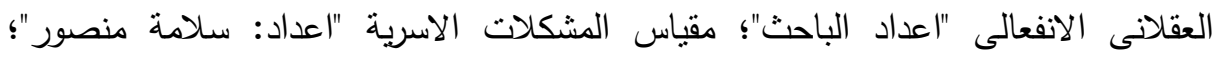
التقارير الطبية والنفسية والاجتماعية للحالة. وتوصلت نتائج الدراسة أنه توجد فروق احصائية دالة بين متوسطات درجات افراد عينة

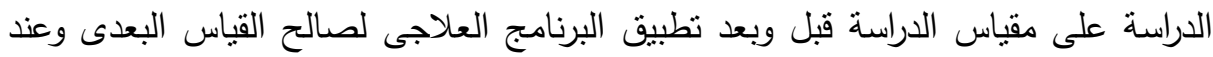

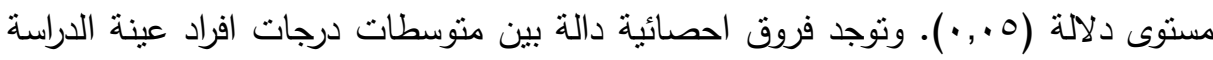

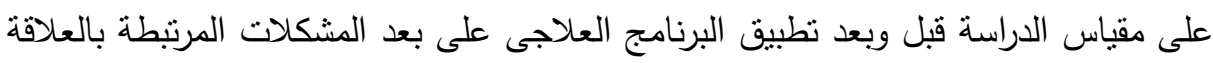

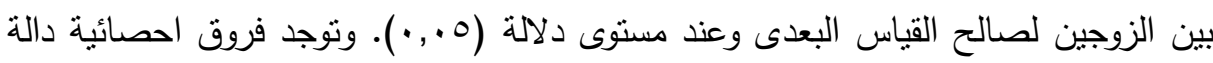
بين متوسطات درجات افراد عينة الدراسة على مقياس الدراسة قبل وبعد نطبيق البرنامج

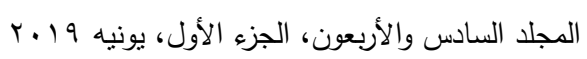


العلاجى على بعد المشكلات المرتبطة بالعلاقة بين الزوجين والابناء لصالح القياس البعدى وعند مسنوى دلالة ( ه...). وتوجد فروق احصائية دالة بين متوسطات درجات افراد عينة

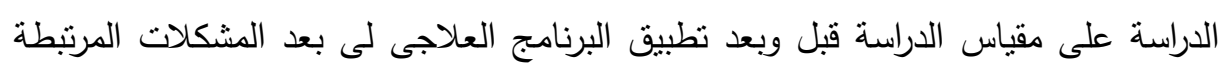
بالعلاقة بين الابناء وبعضهم البعض لصالح القياس البعدى وعند مستوى دلالة (0. ., ).

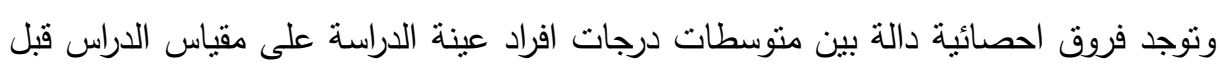
وبعد تطبيق البرنامج العلاجى على بعد المشكلات المرتبطة باسلوب الاسرة فى التنشئة

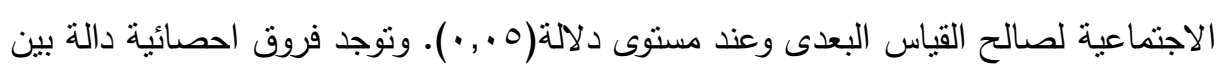

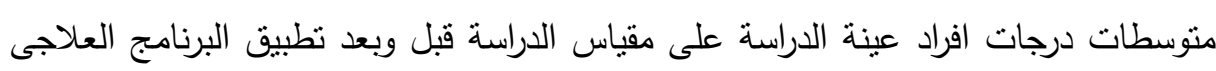

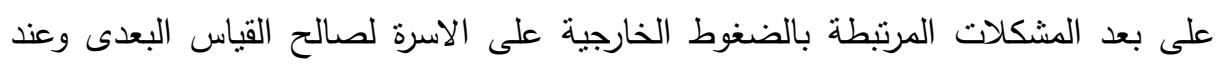

$$
\text { مستوى دلالة (0., (·).) }
$$

بندر العتيبى وزيدان السرطأوى (Y Y • Y): هدفت إلى التعرف على طبيعة الخدمات

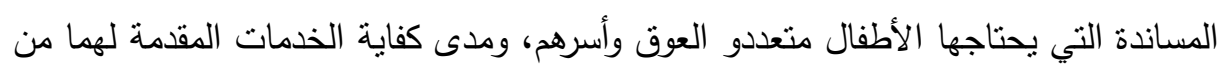
وجهة نظر أولياء الأمور والمعلمين. ولتحقيق هدف الدراسة طبق الباحثان قائمة الخدمات

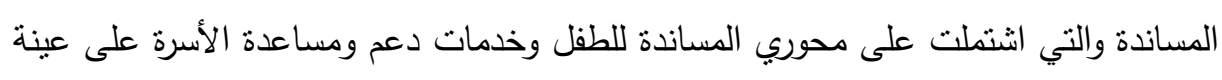
بلغت(7 • (1) من أولياء أمور ومعلمي الأطفال متعددي العوق المسجلين في معاهد ومراكز

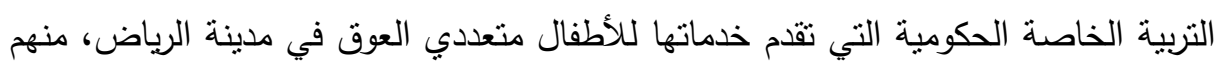

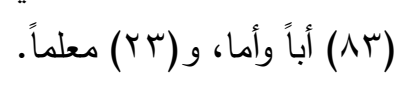

وقد توصلت الدراسة إلى النتائج التالية: عبر أولياء الأمور والمعلمون عن حاجة الأطفال متعددي العوق وأسرهم إلى مختلف الخدمات المنضمنة في قائمة الخدمات المساندة، واتفقا

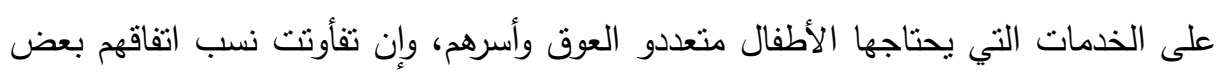

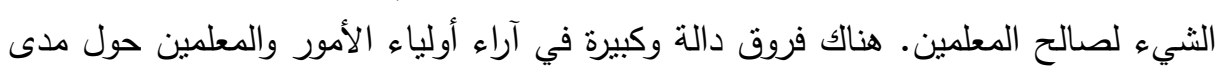

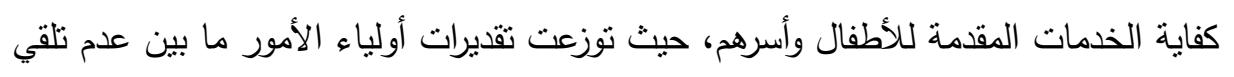

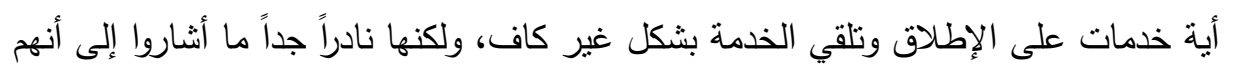
يتلقون الخدمة بدرجة كافيةً. 


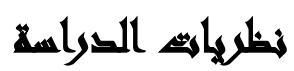

تنبى نظرية الدور على خمس افتراضات أساسية، يوجد عليها اتفاق عام بين العلوم

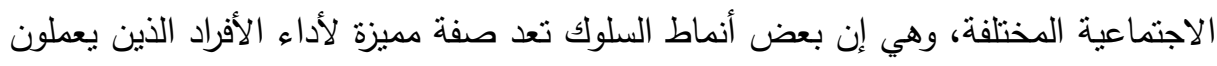

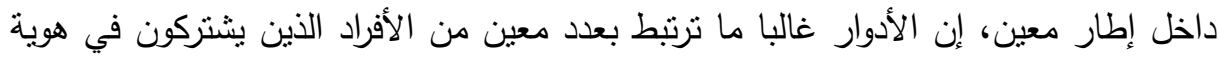
واحدة إن الأفراد غالبا ما يكونون مدركين للاور الذّى يقومون بهان، وإلى حد معين الأدوار يتحكم فيها حقيقة الإدراك بها إن الأدوار تستمر بسبب ما يترتب علئ عليها من نتائج من ناحية

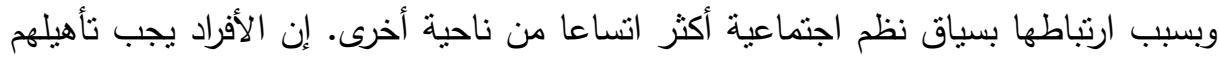
لكأدوار التي يقومون بها. نظرية التعلم بالملاحظة في الوقت الحاضر : إن تصور باندور للتعلم بالملاحظة هو أحد مكونات نظريته في التعلم الاجتماعي، ويقوم في الوقت الحاضر بنوضيح نظرية شاملة

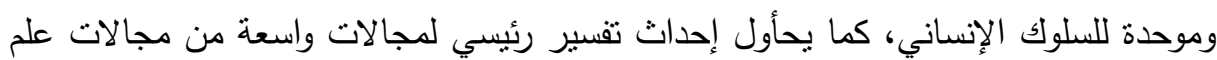
النفس ونظرية التعلم بخاصة، وذلك بتشجيع علماء النفس، من خلال المنطق المحكم، والدلائل

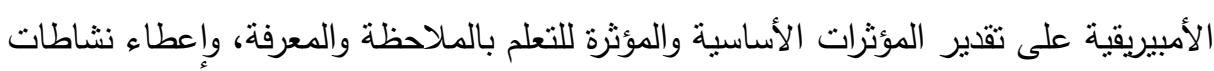
تتظيم الذات حق قدرها، ومنذ عهد قريب أخذت مقولات رئيسة ذات طبيعة نظرية، منل الفعالية

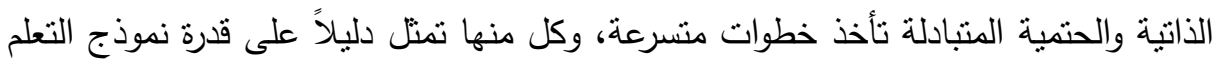

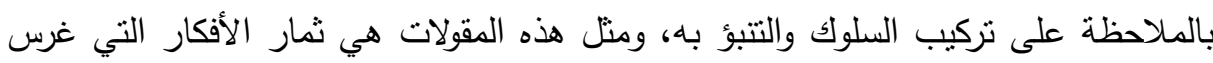

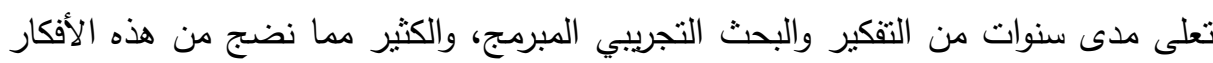
يمكن أن نجدها متضمنة في الأعمال الأولى المتعلقة بظواهر التعلم بالملاحظة.

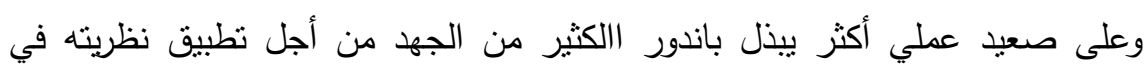
مجال علم النفس الإكلينيكي والتطوري والاجتماعي، وقد أصبحت نطبيقات نظرية مبادئ التعلم

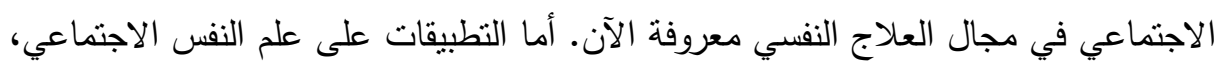
وعلم الأنثروبولوجي النقافية فما زالت في مراحلها الأولية، ونظرية التعلم بالملاحظة كما

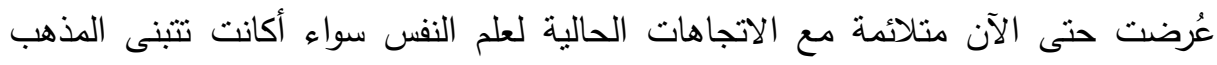

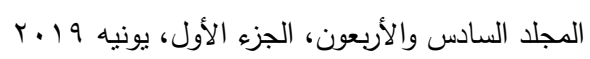


الطبيعي أم المذهب التجريبي، والنظرية تتسجم مع التطورات السائدة إلى الحد الذي ينبغي

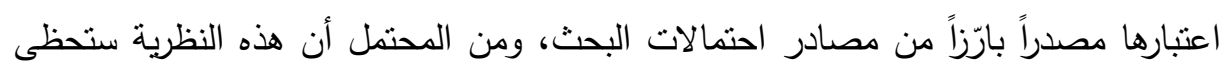

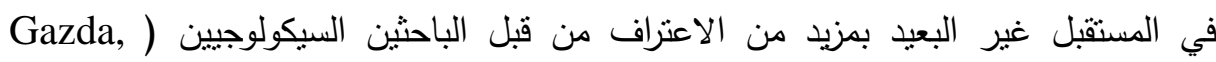

\section{هنهمج التراسة والجراعاتهما}

منهج الاراسة: اعتمد الباحث فى هذه الدراسة على المنهج التجريبى والتصميم التجريبى ذو المجموعتين التجريبية والضابطة والقياس القبلى والبعدى والتتبعى.

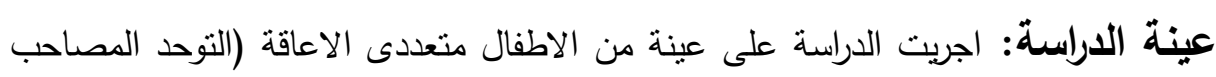

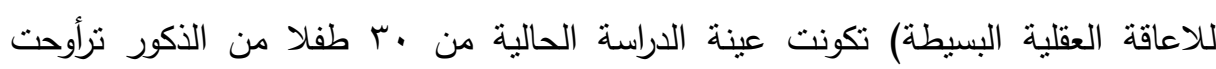

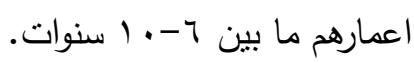
ولقد تم اختيار العينة بطريقة قصديه من مؤسسة قدراتى الدولية للاستشارات والتدريب

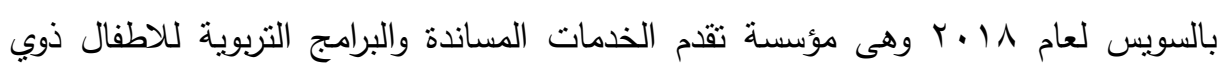
الاحتياجات الخاصة بصفه عامة واسرهم وتم تقسيم العينة قصدياً إلى: (مجموعه ضابطه) تكونت من 10 اطفال ذكور تم تتخيصهم بالتوحد ذو الاعاقة العقلية البسيطة ولم ينلق افراد هذه المجموعه التدريب على البرنامج فى هذه الدراسة. (مجموعة تجريبية) تكونت من 10

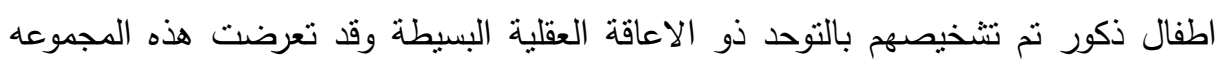

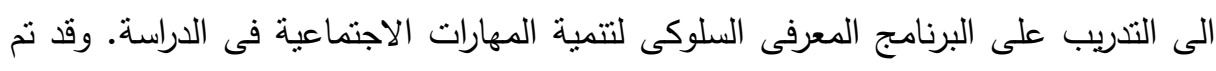

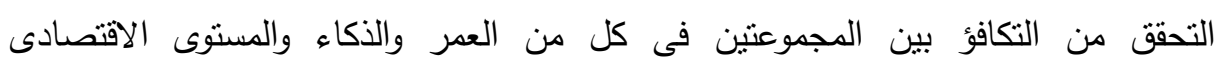
الاجتماعى والثقافى ودرجة التوحد لكل منهم.

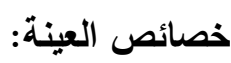
1-ترأوحت اعمار العينة ما بين (7-. (1) سنوات من اطفال مؤسسة قدراتى الدولية

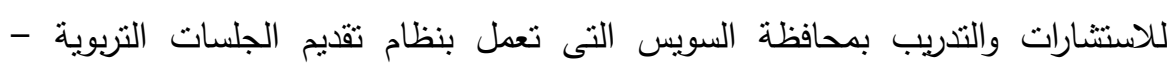
النفسية - التخاطب وتتمية المهارات. 
r-تكونت العينة من الذكور من الاطفال متعددى الاعاقة (التوحد البسيط المصاحب للاعاقة العقلية البسيطة) حيث: قلة اعداد الاطفال الاناث من نفس الفئة؛ ورفض الونئن أولياء أمور

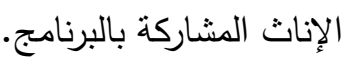

شروط اختيار العينة: راعى الباحثون عند اختيار العينة ان تتوافر فيها الثروط الاتية: 1-ان يكونو من الاطفال التوحديين بدرجة بسيطة وهم مشخصين مسبقا من قبل المؤسسة ونت التاكد من درجة الاعاقة باستخدام مقياس كارز لتتشخيص وتحديد درجة التوحد.

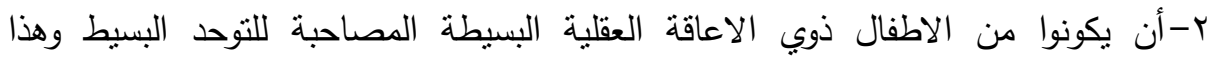

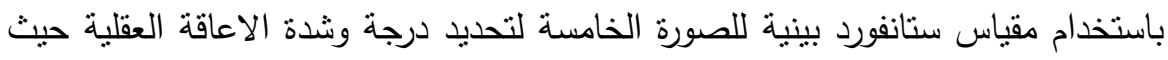

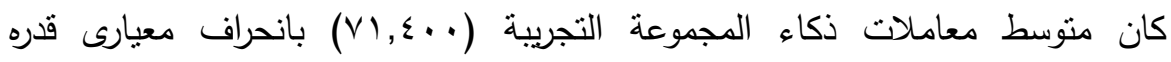

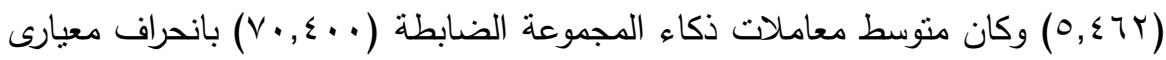

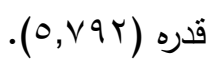
r-ألا يعانى احد افراد العينة من امراض مزمنة أو اية اعاقات اخرى مصاحبة.

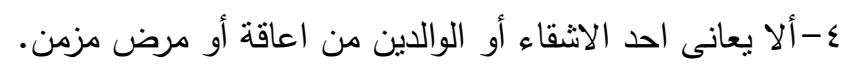

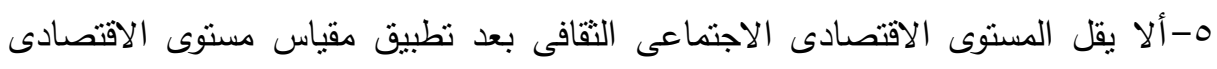

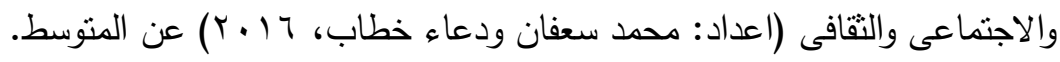
צ- ألا يكون الوالدين منفصلين. V- ألا يكون احد افراد العينة قد شارك فى الى برنامج ارشادى أو تدريبى من قبل.

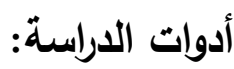
• استمارة البيانات الأولية (اعداد: الباحثون). • مقياس استانفورد بينييه للأكاء الصورة الخامسة: (اعداد: المؤسسة العربية العربية للاختبارات

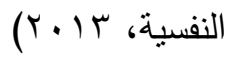
مقياس كارز (C.A.R.S): (اعداد: سكوبلر واخرون 911 ( )) 
• مقياس المهارات الاجتماعية: للاطفال متعددى الاعاقة (اعداد: الباحثون). قام الباحثون

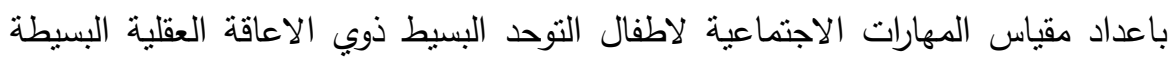
تكونت من سب فقرة ويستخدم من قبل القائمين على رعاية الطفل بحيث يقوم بوضع درجة لاعنة

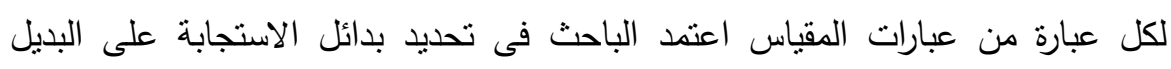
الثلاثى مراعى فى ذلك خصائص العينة وذلك لتتيح فرصة اكبر للعينة لحرية الاختيار

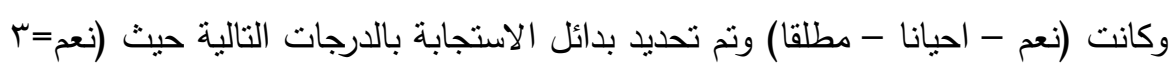

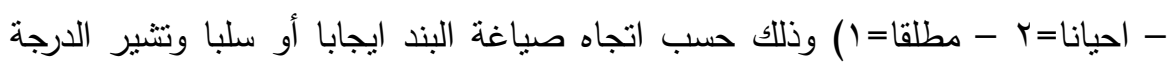
المرتقعه على المقياس الى ارتفاع المهارات الاجتماعية للطفل.

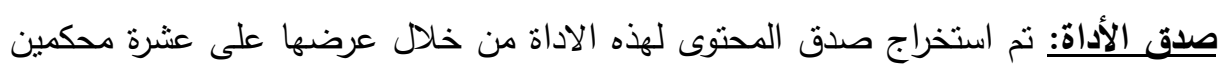

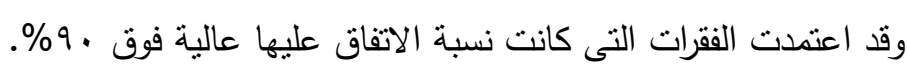

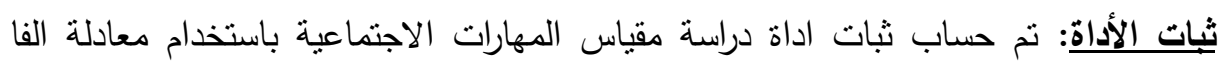

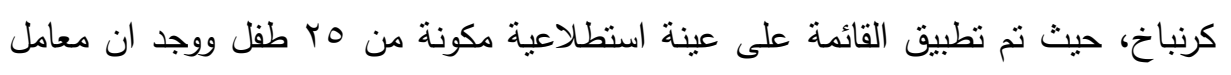
ثناتها يسأوى (ع • ^, •).

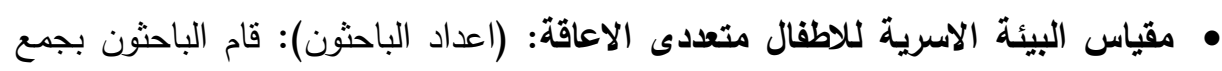

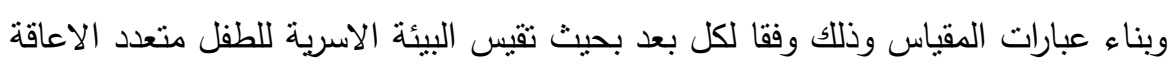
وقد بلغ عدد عبارات المقياس (₹v) عبارة وقد حرص الباحث على ان تكون الاستجابات

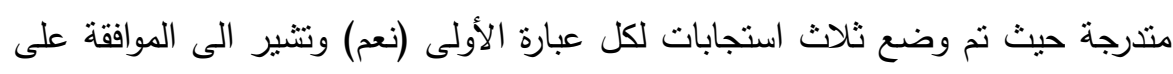
الفقرة بدرجة عالية وحصلت على (r) درجات والثانية (الى حد ما) وتتشير الى الموافقه

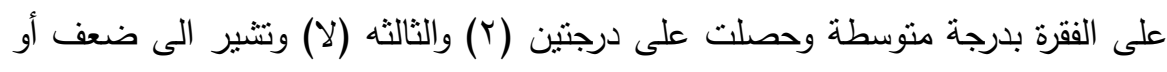

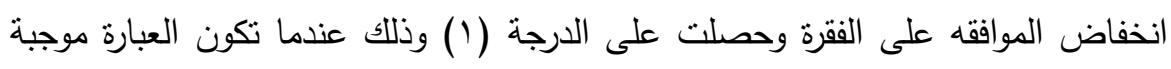

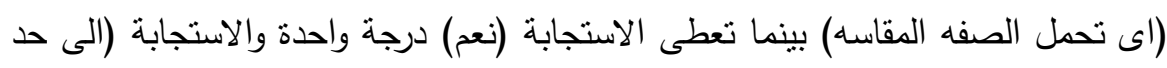

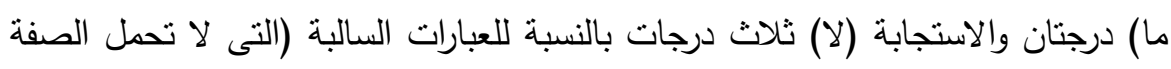
(المقاسة).

صدق الاداة: تم استخراج صدق المحتوى لهذه الاداة من خلال عرضها على (^) محكمين

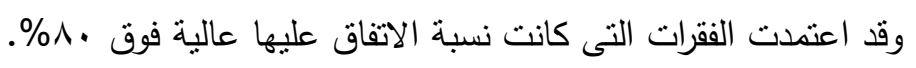


test -retest ثبات الاداة: قام الباحث بحساب ثبات المقياس باستخدام طريقة اعادة الاختبار

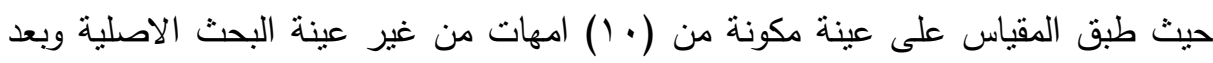

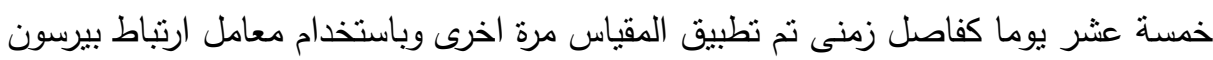

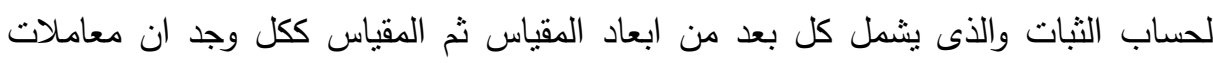

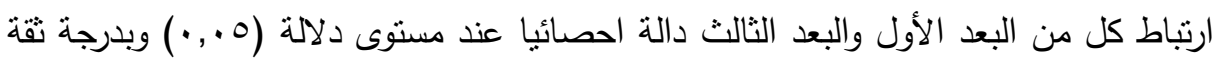
90 فى حين ان معاملات ارتباط كل من البعد الثانى والدرجة الكلية لذات المقياس دالة

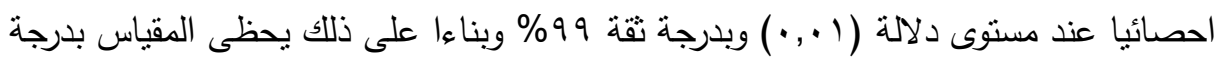
عالية من الثبات.

البرنامج المعرفى السلوكى المقترح لتنمية المهارات الاجتماعية لدى الاطفال ذوي الاعاقة

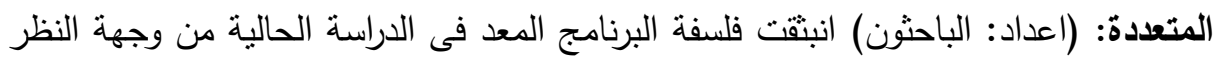

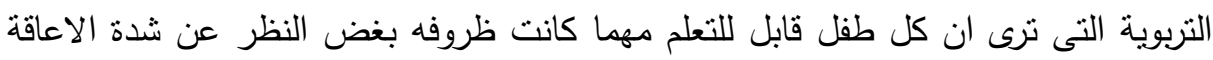

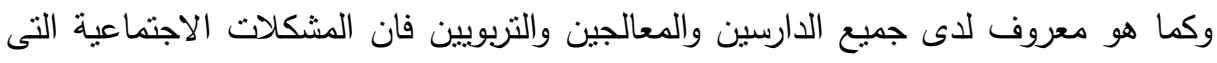
يعانى منها الطفل التوحدى ذو الاعاقة العقلية البسيطة تعتبر الاصعب من بين الششكلات

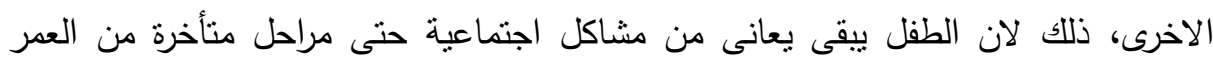

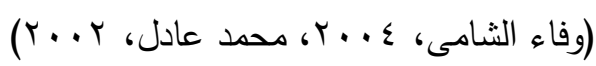
وبناء على ما تقدم قام الباحثون باعداد البرنامج المعرفى السلوكى بهدف تتمية المهارات الاجتماعية للاطفال التوحديين ذو الاعاقة العقلية البسيطة وتتمثل هذه المهارات فى مهارة الاستعداد للتعلم (التواصل البصرى، وزيادة فترة الانتباه، واتباع الأوامر البسيطة) والمهارات

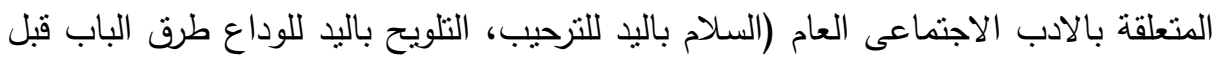

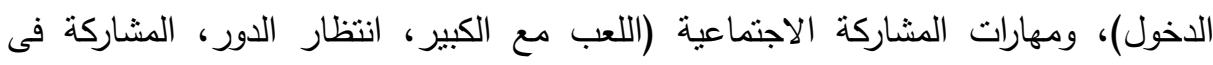
النشاط المنظم مع الاطفال). وقد مر بناء البرنامج بعدد من الخطوات التى سبقت ظهوره بالصورة النهائية التى طبق فيها كما يلىى: 
1-مراجعة الاطر النظرية النى تتحدث عن خصائص الاطفال التوحيين ذو الاعاقة العقلية البسيطة بشكل عام والخصائص الاجتماعية بشكل خاص واساليب تدريبهم (الثامى،

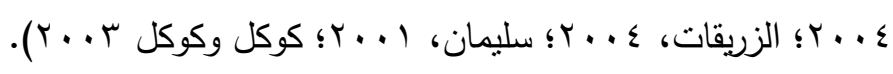

r-الاطلاع على الاساس النظرى الذى يتحدث عن كيفية اداء وتصميم البرامج التربوية

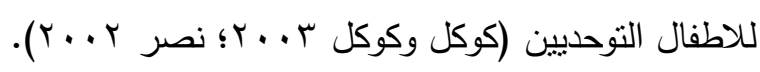

r-الاطلاع على الادب السابق والدراسات التى اهتمت بتتمية المهارات الاجتماعية للاطفال

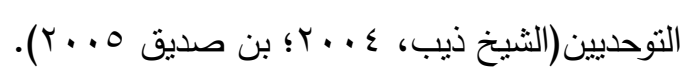

ع-الاطلاع على بعض البرامج التربوية التى تهتم بتعليم المهارات الاجتماعية للاطفال

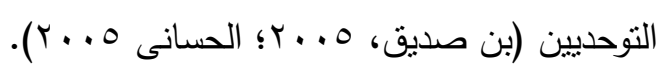

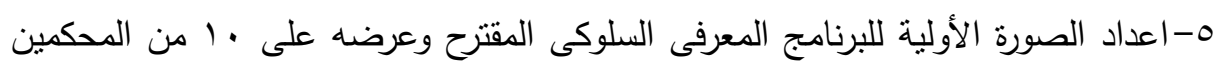

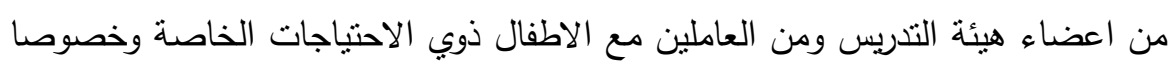

$$
\text { فئة عينة الدراسة لابداء الراى وتعديل ما يرونه مناسبا. }
$$

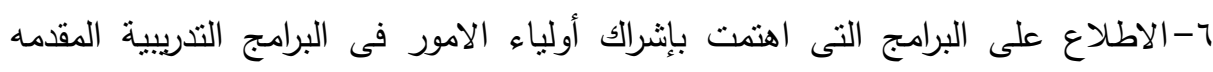

للاطفال ذوي الاحتياجات الخاصة (التوحديين - الاعاقه العقلية البسيطة).

المعالِجات الْإحصائية المستخدِمة فِي الدّراسة: لتحقيق أهداف الدراسة وتحليل البيانات التي تم تجميعها، فقد تم استخدام الأساليب الإحصائية المناسبة باستخدام برنامج

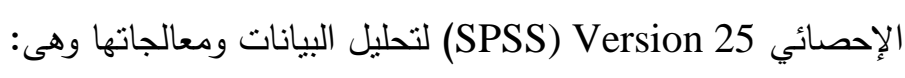
1- المعامل الفا كرونباخ r- ب المتوسطات r- ب- الانحراف المعيارى ع- معامل ارتباط بيرسون ه- اختبار مان ويتتى اللابارامترى لدلالة الفروق بين المجموعات المستقلة 1-اختبار (ويلكوكسون) اللابارامترى لدلالة الفروق بين المجموعات المرتبطة 


\section{نئائج الصراسة}

الفرض الأول: ينص على "توجد فروق دالة احصائيا بين منوسطات رتب درجات المجموعة التجريبية والضابطة من الاطفال فى القياس بعد تطبيق البرنامج على مقياس المهارات الاجتماعية فى اتجاه المجموعة التجريبية" وللتأكد من صدق هذا الفرض بط لطن حسب الباحث اختبار

(مان وينتى) اللابارامترى لدلالة الفروق بين المجموعات المستقلة، ويوضح ذلك جدول (1) (1) جدول (1): متوسطات الرتب ومجموعها وقيم (Z, U) ودلالتها بين المجموعتين التجريبية والضابطة فى القياس بعد البرنامج على مقياس المهارات الاجتماعية

\begin{tabular}{|c|c|c|c|c|c|c|c|}
\hline \multirow{2}{*}{ الدلالئي } & \multirow{2}{*}{ قيمة } & \multirow{2}{*}{ قيمة } & \multicolumn{2}{|c|}{ 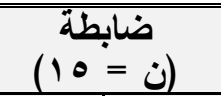 } & \multicolumn{2}{|c|}{$\begin{array}{c}\text { تجريبية }(10) \\
(10)\end{array}$} & \multirow{2}{*}{ القيم } \\
\hline & & & رجموع & متوسط & رجموع & متوسط & \\
\hline$\cdot, \ldots 1$ & $\varepsilon, V \backslash 9$ & صفر & IT. & $\wedge$ & $r \leqslant 0$ & $r r$ & الاستعداد للتعلم \\
\hline$\cdot, \ldots 1$ & $\varepsilon, V T \mu$ & صفر & $\pi$ & $\Lambda$ & $r \leqslant 0$ & $\overline{Y T}$ & الاداب العامة \\
\hline$\cdot, \ldots$, & $\varepsilon, 7 \cdot Y$ & $r$ & $T$ T. & $\Lambda$ & $r \leqslant 0$ & Tr & المشاركة الاجتماعية \\
\hline$\cdot, \ldots 1$ & $\varepsilon, V \Gamma \varepsilon$ & صفر & Tr. & $\Lambda$ & $r \leqslant 0$ & r & الدرجة الكلية \\
\hline
\end{tabular}

أنشارت نتائج جدول (1) الى وجود فروق دالة إحصائيا بين متوسطات رثب درجات المجموعتين التجريبية والضابطة على مقياس المهارات الاجتماعية (الاستعداد للتعلم، الاداب

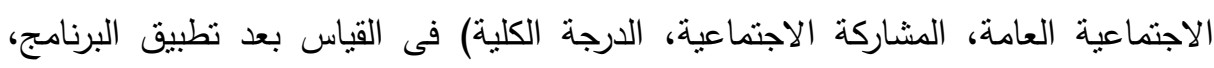
وذللك فى اتجاه المجموعة التجريبية.

وقد يرجع نجاح البرنامج إلى تتوع وتكامل الأهداف التى تعمل على تتمية بعض انجله المهارات الاجتماعية وهذا يتفق مع ما اكدته دراسة فيليب ستراين ومارلين هوسن (ب.... (Y) لاهمية توافر برامج التذخل فى السلوك الاجتماعى واللغه لصالح المجموعة التجريبية كما لهابه

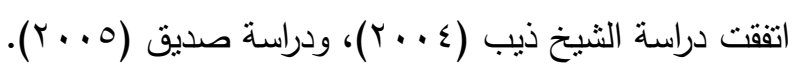

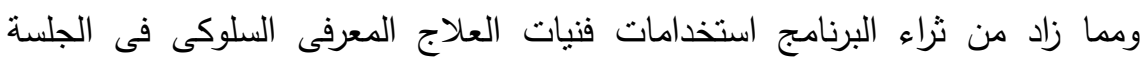
النموذج كالاقتداء ولعب الادوار والحوار والمناقثة والواجب المنزلى والنمذجة وتعديل الافكار

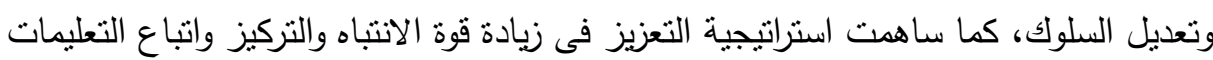

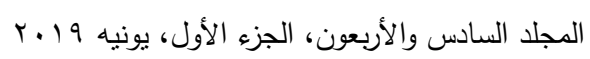


الموجهه اليه بدقه والتى تحث الاطفال على الاستمرار فى ممارسة العادات الاجتماعية فى مواقف الحياة المختلفة بفعالية. الفرض الثانى: ينص على "توجد فروق دالة احصائيا بين متوسطات رثب درجات المجموعة التجريبية من الاطفال ذوي الاعاقة المتعددة فى القياسين قبل وبعد تطبيق البرنامج

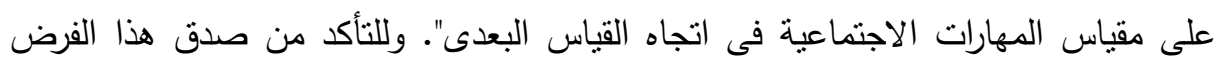

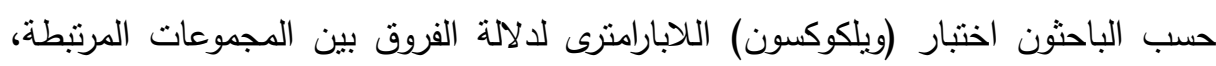
يوضح ذلك جدول (r) (ب). جدول (Y): متوسط الرتب مجموعها وقيم (Z,W) ودلالتها بين القياسين قبل وبعد تطبيق

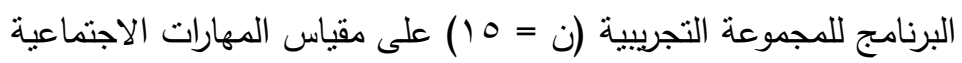

\begin{tabular}{|c|c|c|c|c|c|c|c|}
\hline \multirow[b]{2}{*}{ الدلالئة } & \multirow{2}{*}{ قيمة } & \multirow{2}{*}{ قيمة } & \multicolumn{2}{|c|}{ قَياس بعدى } & \multicolumn{2}{|c|}{ قياس قبلى } & المجموعة والقيه \\
\hline & & & رجبوع & رتبط & رجبموع & رتوسط & المهارة \\
\hline$\cdot, \ldots 1$ & $r, \Sigma Y \wedge$ & صفر & $\overline{T H .}$ & 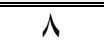 & صفر & صفر & الاستعداد للتعلح \\
\hline$\cdot, \ldots 1$ & $r, \Sigma Y r$ & صفر & 1.0 & $V, 0$ & صفر & صفر & الاداب العامة \\
\hline$\cdot, \cdots$, & r,r) & صفر & Tr. & $\Lambda$ & صفر & صفر & المشاركة الاجتماعية \\
\hline$\cdot, \ldots 1$ & $r, \varepsilon Y \tau$ & صفر & $T r$. & $\Lambda$ & صفر & صفر & الارجة الكلية \\
\hline
\end{tabular}

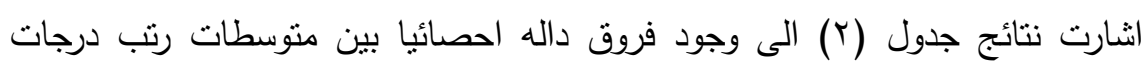
المجموعة التجريبية من الاطفال ذوبي الاعاقة المتعددة على مقياس المهارات الاجتماعية

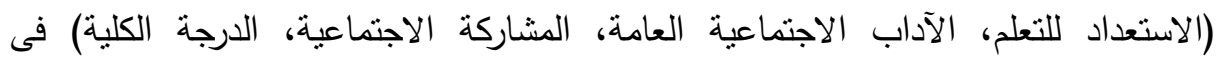

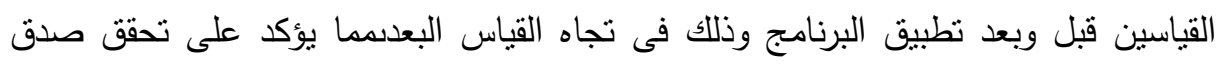
الفرض الثانى وقد ترجع نتائج هذا الفرض الى استخدام العديد من الانشطة سواء من خلاد

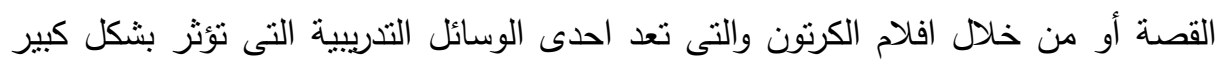

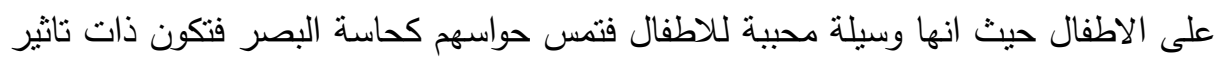

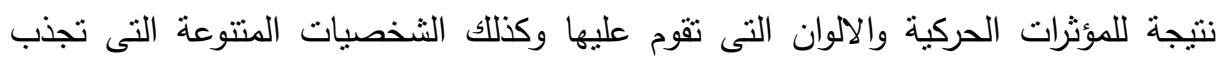

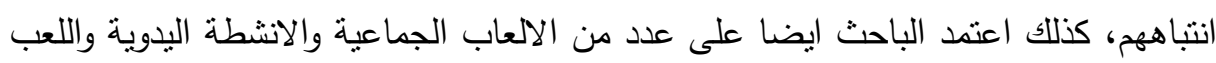

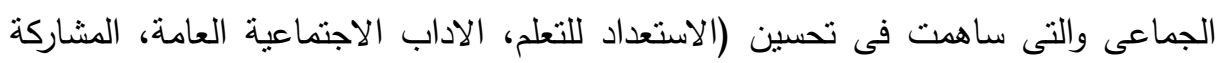

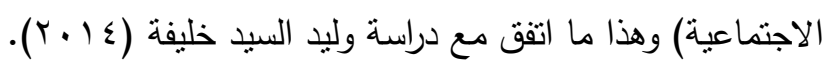


الفرض الثالث: ينص على "لا توجد فروق دالة احصائيا بين متوسطات رثب درجات المجموعة التجربية من الاطفال ذوي الاعاقة المتعددة فى القياسين البعدى والتتبعى لتطبيق البرناج على مقياس المهارات الاجتماعية". وللتأكد من صدق هذا الفرض حسب التب الباحث اختبار (ويلكوكسون) اللابارامترى لدلالة الفروق بين المجموعة المرنبطة، ويوضح ذلك جدول

جدول (r): متوسطات الرتب ومجموعها وقيم (Z, و) ودلالتها بين القياسين البعدى والتتبعى لتطبيق البرنامج للمجموعة التجريبية ن = 10 على مقياس المهارات الاجتماعية

\begin{tabular}{|c|c|c|c|c|c|c|c|}
\hline \multirow{2}{*}{ الدلالية } & \multirow{2}{*}{ قيمة } & \multirow{2}{*}{ قيمة } & \multicolumn{2}{|c|}{ قياس تتبعى } & \multicolumn{2}{|c|}{ قياس بعدى } & \multirow{2}{*}{ المهارة } \\
\hline & & & رجبوع & متوسط & رجموع & متوسط & \\
\hline غير دال & $\cdot, \wedge \uparrow \wedge$ & $\varepsilon, 0$ & $1 \cdot, 0$ & T,TY & $\varepsilon, 0$ & $\varepsilon, 0$ & الاستعداد للتعلد \\
\hline غير دال & $\cdot, 0 \wedge \mathrm{V}$ & $1 \varepsilon$ & YY & 0,0 & $1 \varepsilon$ & $r, 0$ & الاداب العامة \\
\hline غير دال & $\cdot, \varepsilon) \leqslant$ & 7 & 7 & r & 9 & $\varepsilon, 0$ & المشاركة الاجتماعية \\
\hline غير دال & $\cdot, 9 \vee \mu$ & 7 & 10 & $r, \vee 0$ & 7 & $r$ & الدرجة الكلية \\
\hline
\end{tabular}

اشارت نتائج جدول (r) الى عدم وجود فروق دالة احصائيا بين منوسطات رتب درجات المجموعة التجريبية على مقياس المهارات الاجتماعيه (الاستعداد للتعلم، الاداب الاجتماعية العامة، المشاركة الاجتاعية، الدرجة الكلية) فى القياسين البعدى والتتبعى لتطبيق البرنامج.

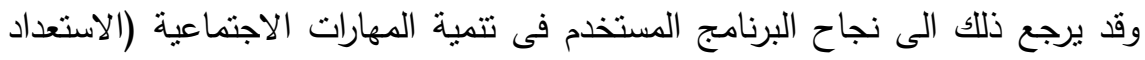

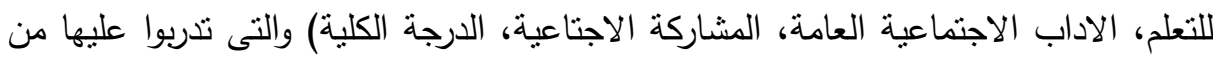

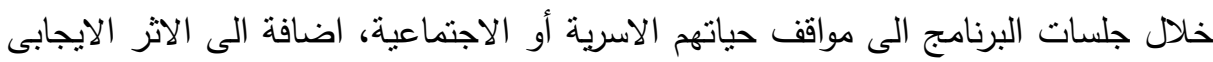

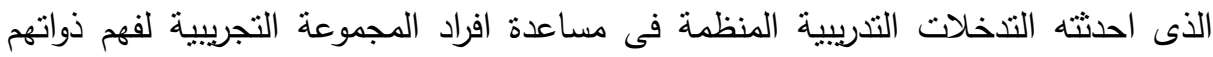
وادراكهم لقدراتهم وما يمتلكون من مهارات والوعى للبيئة التى يعيشون فيها واستغلال ما لديهم من امكانيات ذاتية وبيئية وتوظيفها لتحقيق التوافق الاجتماعى والتفاعل الايجابى وتحقيق

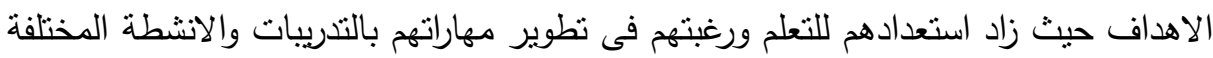
مما ساعد على زيادة ادراكهم وانتباههم اثثاء ممارسة الانشطة بالبرنامج كما زادت مهارئه بهاراتهم للعادات الاجتماعية العامة وحسن المعاملة والتصرف عند زيارة الاهل والاستجابة لتوجيهات

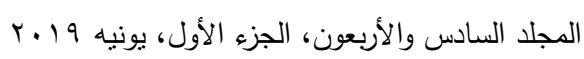


الاسرة بالاضافة الى تحسين المهارات الاجتماعية المتعلقة بالمشاركة الاجتماعية كاحتضان

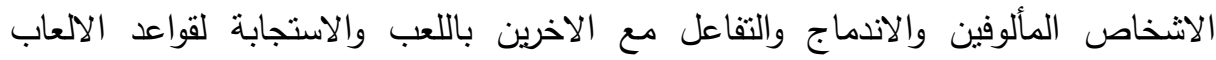
الجماعية والتقليد مما يعنى استمرار اثر البرنامج وفاعليته بعد فترة من الزمن فى محأولة تتمية بعض المهارات الاجتماعية لاى الاطفال متعددى الاعاقة. الفرض الرابع: ينص على "توجد فروق دالة احصائيا بين متوسطات رتب درجات المجموعة

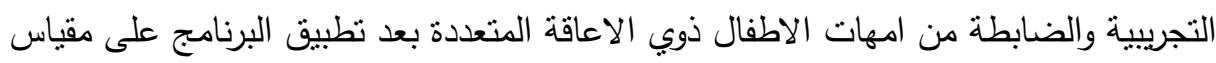

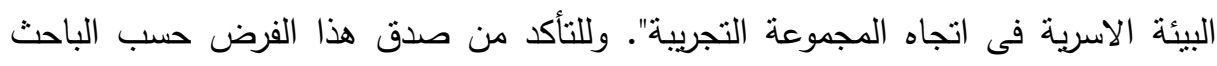
اختبار (مان وينتى) اللابارامترى لدلالة الفروق بين المجموعات المستقلة، كما هو موضح

جدول (ء): متوسطات الرتب ومجموعها وقيم (Z, U) ودلالتها بين المجموعتين التجريبية

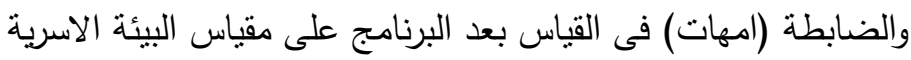

\begin{tabular}{|c|c|c|c|c|c|c|c|}
\hline \multirow{2}{*}{ الدلالئي } & \multirow{2}{*}{ قيمة } & \multirow{2}{*}{ قيمة } & \multicolumn{2}{|c|}{ ضابطة (ن=0 1 ) } & \multicolumn{2}{|c|}{ تجريبية (ن=0 1 1) } & \multirow{2}{*}{ المجموعة المهارة } \\
\hline & & & رجبوع & متوبط رتب & رجبوع & متوبط رتب & \\
\hline$\cdot, \ldots 1$ & $\Gamma, \wedge \varepsilon$ & $r, \ldots$ & ov & $0, v$. & 197 & $17, \pi \mu$ & التقبل \\
\hline$\cdot, \ldots 1$ & $r, 0 \leqslant$ & 7,0 & $71,0$. & 7,10 & 191 & 10,97 & المسأواة \\
\hline., .0 & $\overline{r, V \mu}$ & 19 & $V \varepsilon, \ldots$ & $\vee, \varepsilon$. & $19 V$ & $1 \varepsilon, 9 Y$ & الاتساق \\
\hline$\cdot, \cdot 1$ & $r, \varepsilon r$ & $r \mu, 0$. & $\vee \wedge, 0$. & $\vee, \wedge 0$ & $\mid V \varepsilon, 0$ & $1 \leqslant, \leqslant 0$ & الدرجة الكلية \\
\hline
\end{tabular}

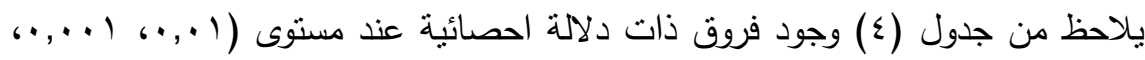
ه . . •) بين متوسطات رتب درجات امهات المجموعة التجريبية والضابطة على مقياس البيئة

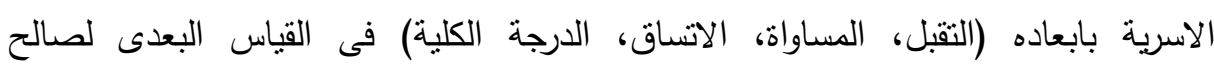
المجموعة التجريبية.

وقد ترجع نتائج هذا الفرض الى الاهداف التى عمل البرنامج على تحقيقها، والانشطة

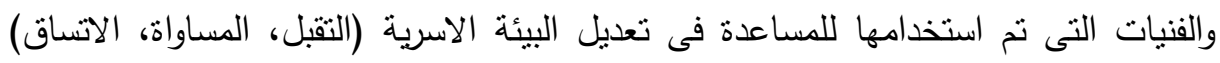
وهذا ما ادى الى الاختلاف بين درجات المجموعة التجريبية لجلسات وانشطة البرنامج

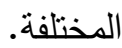


ويرجع ذلك الى الاثر الايجابى لبرنامج التدخل المهنى باستخدام العلاج المعرفى السلوكى، وهذا ما يجعل للبرنامج المعرفى السلوكى اهية فى تدخله لتعديل البيئة الاسرية بلهية

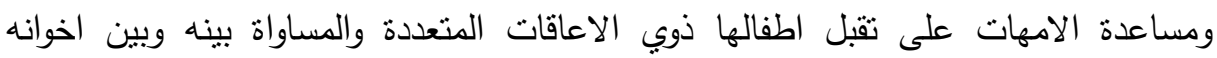
والاتساق فى المعاملة بين افراد الاسرة له حتى تخرج الاسرة من دائرة الضغوط الضعاع النفسية

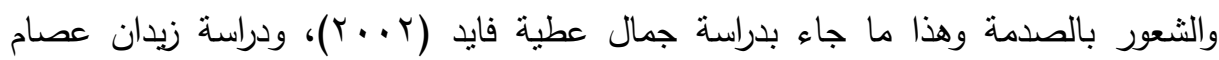

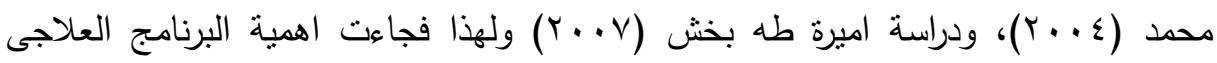
المعرفى السلوكى لتعديل البيئة الاسرية حيث الدعم الاجتماعى للأسر وتكوين مدركات ايجابية

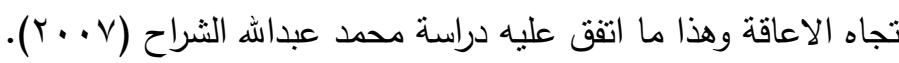
الفرض الخامس: ينص على "توجد فروق دالة احصائيا بين منوسطات رتب درجات المجموعة التجريبية من امهات الاطفال ذوي الاعاقة المتعددة فى القياسين قبل وبعد نطبيق البرنامج على مقياس البيئة الاسرية فى اتجاه القياس البعدى". وللتاكد من صدق هذا الفرض الته حسب الباحث اختبار (ويلكوكسون) اللابارامترى لدلالة الفروق بين المجموعات المرتبطة،

ويوضح ذلك جدول (0) جدول (0): متوسط الرتب مجموعها وقيم (Z, و) ودلالتها بين القياسين قبل وبعد تطبيق البرنامج للمجموعة التجريبية (امهات) (ن = م 1) على مقياس البيئة الأسرية

\begin{tabular}{|c|c|c|c|c|c|c|c|}
\hline \multirow{2}{*}{ الدلائة } & \multirow{2}{*}{ قيمة } & \multirow{2}{*}{ قيمة } & \multicolumn{2}{|c|}{ قياس بعدى } & \multicolumn{2}{|c|}{ قياس قبلى } & المجموعة \\
\hline & & & مجموع & متوبط رتب & رجبوع & متوبط رتب & المهارة \\
\hline$\cdot, \cdot 1$ & $\overline{r, T V}$ & $09, Y \leqslant$ & $\bar{N} \lambda \cdot, \xi$ & $1 \Psi, \varepsilon$ & $r \varepsilon, \wedge\rceil$ & $0, \wedge 1$ & التقبل \\
\hline$\cdot, \cdot 1$ & $r, .0$ & $O Y, \Lambda$ & 91,1 & $10, r$ & $\varepsilon, V \varepsilon$ & 7,19 & المسأواة \\
\hline$\cdot, \cdot 1$ & $r, 90$ & Or, & $\lambda q, \varepsilon$ & $1 \leqslant, 9$ & $\sum r, r q$ & $\overline{V, Y I}$ & الاتساق \\
\hline$\cdot, \cdot 1$ & T,9Y & $\overline{07,11}$ & $91, r$ & $10, Y$ & $r \wedge, r \varepsilon$ & $7, \Gamma 0$ & الدرحة الكلية \\
\hline
\end{tabular}

أثنارت نتائج جدول (0) إلى وجود فروق داله إحصائيا بين منوسطات رتب درجات المجموعة التجريبية من أمهات الاطفال ذوي الاعاقة المتعددة على مقياس البيئة الاسرية (النقبل، المساواة، الاتساق، الدرجة الكلية) فى القياسين قبل وبعد تطبيق البرنامج وذلك فى الى

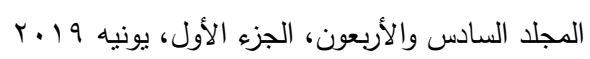


تجاه القياس البعدمما يؤكد على تحقق صدق الفرض ويدل ذلك على ان التغييرات والتعديلات التى طرأت على امهات المجموعة التجريبية تغييرات جوهرية وترجع الى التذخل المهنى ولان ترجع الى عوامل الصدفة لانها حدثت بنسبة اكبر من نلك التى حدثت لامهات المجموعة

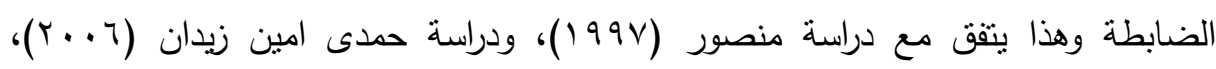

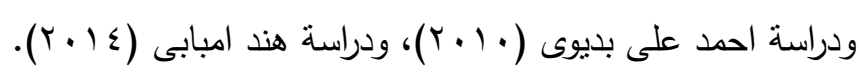

\section{المئوسيامت}

() تدريب أسر الاطفال ذوي الاعاقة المتعددة من خلال ورش عمل ودروات ندريبية واشراكهم

$$
\text { فى تخطيط وتتفيذ البرنامج التربوى. }
$$

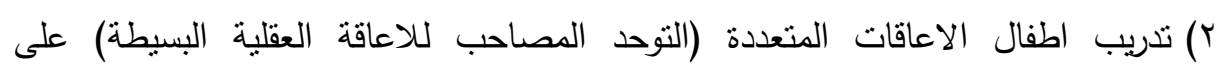
المهارات الاجتماعية فى عمر مبكر بما يعينهم على الاعتماد على النفس فى حياتهم اليومية.

r) القيام بدراسات تهتم بتطوير برامج تدريبية بهدف تتمية المهارات الاجتماعية لاطفال الاعاقات المتعددة.

\section{المراليج}

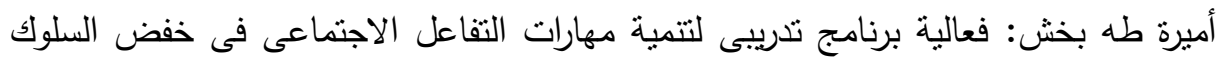

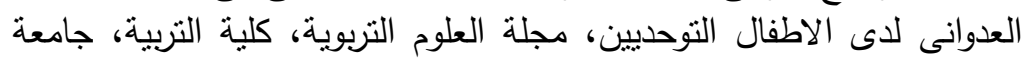

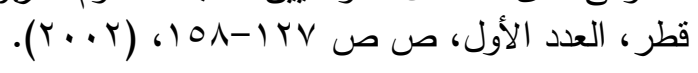

بندر بن ناصر العتيبى وزيدان زايد السرطاوى: الخدمات المساندة التي يحتاجها الاطفال

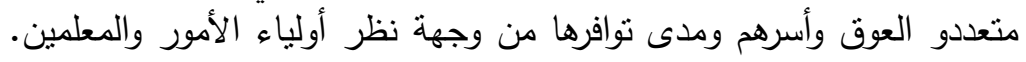

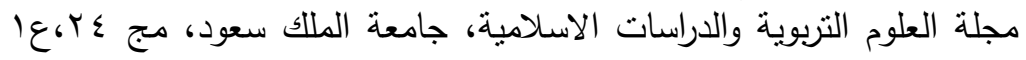

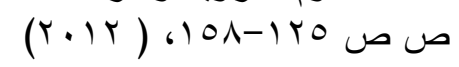

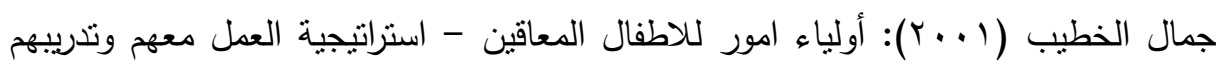
ودعمهم، الرياض، اكاديمية التربية الخاصة، المعلكة العربنة العربية السعودية. 


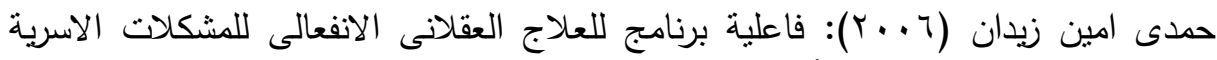

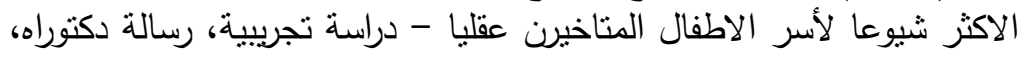

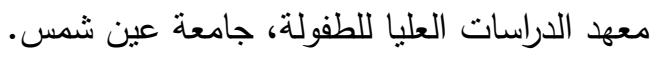

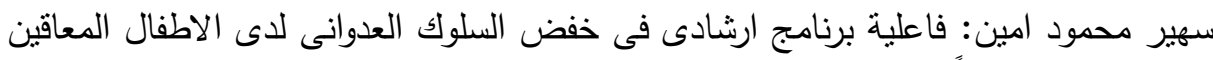

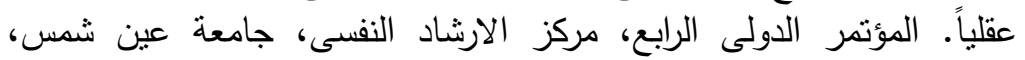

$$
\cdot(r \cdot V)
$$

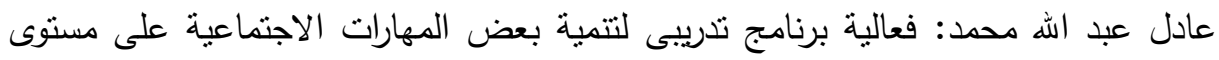

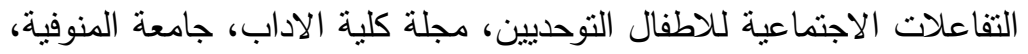

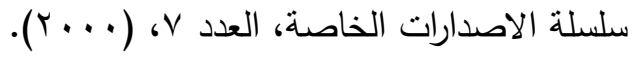

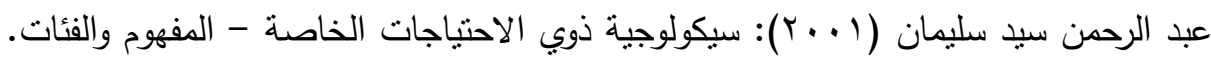

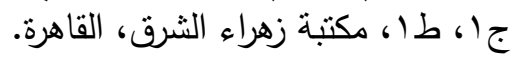

ليلى كرم الدين (990 (190): مدى كفاءة وفاعلية برنامج تربوى للتنمية العقلية واللغوية لعينة من الاطفال المعاقين عقلياً.

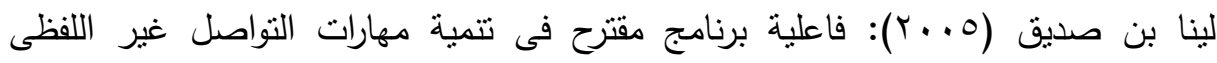

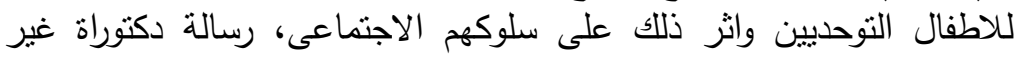
منشورة، الجامعة الاردنية.

محمد الظريف سعد: مقياس الاتجاهات نحو الاتتماء الى جماعة. المؤتتر العلمى الثالث، كلية الخدمة الاجتماعية جامعة حلوان - القاهرة، (1919 (1)).

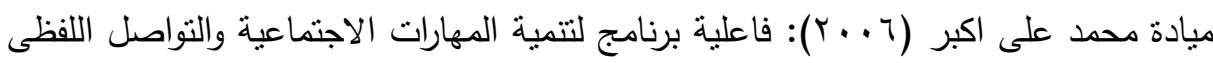

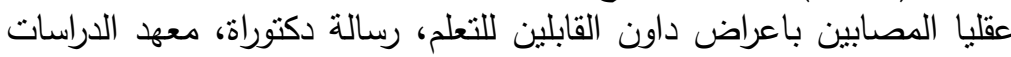
العليا للطفولة.

Kendall, Philip, C. (2000): Childhood disorders. UK; East Sussex Psychology press Ltd, publishers.

Gazda; Raymond, J. Corsini, B. (1983): Home based behavioral treatment goyoung children with autism. Journal of Autism and Developmental Disorders, 28, (1). 15 - 25 . 


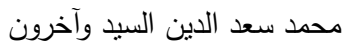

\title{
EFFECTIVENESS OF A BEHAVIORAL COGNITIVE PROGRAM TO DEVELOP SOCIAL COMMUNICATION SKILLS AND MODIFY THE FAMILY ENVIRONMENT FOR PEOPLE WITH MULTIPLE DISABILITIES
}

\author{
Mohamed, S. El-Sayed ${ }^{(1)}$; Asmaa, M. El-Sersy ${ }^{(2)}$ \\ and Mohamed, A. Elsawy ${ }^{(3)}$
}

1) Post graduate, Institute of Environmental Studies \& Research, Ain Shams University 2) Faculty of Childhood, Ain Shams University 3) Faculty of Medicine, Ain Shams University

\begin{abstract}
The present study aimed at verifying the effectiveness of a behavioral knowledge program for the development of social communication skills and modification of the family environment in a sample of children with multiple disabilities and their mothers in Suez City, Egypt. The study was based on the experimental method. The study sample consisted of two groups (experimental - Children with multiple disabilities (simple autism concomitant with disabilities) ranged from 6-10 years of age to 65-75 degrees. The study tools consisted of the Stanford Intermediate Intelligence Scale, the fifth picture (by the Arab Psychological Testing Institute) D (by: Escoblr and others)- Scale Social Skills (by: researchers) - Family Environment Scale (by: researchers) and cognitive behavioral program proposed for the development of social skills (by: researchers). The researcher used to study the study hypotheses, arithmetical averages and standard deviations of the experimental and control groups, as well as the use of the method of analysis of variance. The theories in the study include role theory, social participation theory, communication theories in psychology and social sciences.
\end{abstract}

$$
\text { المجلد السادس والأربعون، الجزء الأول، يونيه } 19 \text { ـ. }
$$




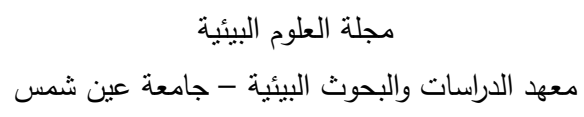

The results of the study were summarized in the following points: There are statistically significant differences between the mean scores of the experimental group and the control of the children in the measurement after the application of the program on the scale of social skills in the direction of the experimental group. There are statistically significant differences between the mean scores of the experimental group scores of children with multiple disabilities in the measurements before and after the application of the program on the scale of social skills in the direction of distance measurement. There are no statistically significant differences between the average grades of the experimental group of children with multiple disabilities in the dimensions of dimension And follow-up to the application of the program on the scale of social skills. There are statistically significant differences between the average scores of the tribal and the barricades of the experimental group (mothers) on the scale of the family environment of the multi-disability child. There are no statistically significant differences between the averages Type degrees group experimental mothers of children with multiple disabilities in the two measures after and observable for the application of the program on the Family Environment Scale.

The study recommended: Training the families of children with multiple disabilities through workshops and training courses and engaging them in the planning and implementation of the educational program. Training children with multiple disabilities (autism associated with simple mental disability) on social skills at an early age, which helps them to rely on themselves in their daily lives. Conducting studies to develop training programs aimed at developing the social skills of children with multiple disabilities. 